\title{
Step-by-step social life cycle assessment framework: a participatory approach for the identification and prioritization of impact subcategories applied to mobility scenarios
}

\author{
Ghada Bouillass $^{1}$ (D) Isabelle Blanc ${ }^{1}$ (D) Paula Perez-Lopez ${ }^{1}$ (D)
}

Received: 7 June 2021 / Accepted: 30 September 2021 / Published online: 10 November 2021

(c) The Author(s) 2021

\begin{abstract}
Purpose Investigating potential social and socio-economic impacts should play a key role for the development of sustainable mobility alternatives. Social life cycle assessment (S-LCA) is becoming increasingly important to ensure holistic sustainability assessments. The present work aims at identifying and evaluating social and socio-economic impact subcategories in S-LCA. A novel participatory approach implying all concerned stakeholders is proposed to select relevant impact subcategories and thus contribute to a thorough interpretation of S-LCA results. It is applied to assess electric and conventional vehicles.

Methodology This paper describes a comprehensive step-by-step S-LCA framework. The innovation of this work consists in defining a structured S-LCA framework integrating a systematic approach based on two stages: (1) a sectorial risk analysis for the identification of impact subcategories and (2) a participatory approach for their prioritization. The proposed participatory approach considers all concerned stakeholders to enable the selection of the most relevant impact subcategories. A set of social inventory indicators is attributed to subcategories that were perceived as the most relevant. These are used to perform the social evaluation and carry out a full analysis in the result interpretation allowing thus to integrate a multi-actor perspective to the materiality assessment.

Results The defined S-LCA framework is implemented to compare two mobility scenarios, corresponding to electric and conventional vehicle technologies. A new set of mobility-related impact subcategories is proposed for users' stakeholder. Following the new designed participatory approach, subcategories for all stakeholders are prioritized according to different actors' perceptions. For example, "safe and healthy living conditions," "local employment," and "delocalization and migration" were perceived for local communities as the most relevant subcategories by the different consulted stakeholders (industrial, academic, and public actors and users). These results also showed that social significance varies depending on the consulted actors and on the geographical area of the study. Using PSILCA database, we have investigated the subcategories that were perceived as the most relevant. Results for the evaluation and interpretation phases are presented for both transportation technologies.

Conclusions This approach aims at increasing local relevance of S-LCA results and their representativeness. Results for the considered mobility scenarios have demonstrated the need to extend the scope of the materiality assessment, generally used for determining subcategories' social significance from a single stakeholder perspective, by involving other stakeholders into the prioritization stage. Moreover, the proposed comprehensive S-LCA framework integrating the participatory approach is general enough to be applied to other product systems and sectors.
\end{abstract}

Keywords S-LCA · Participatory approach $\cdot$ Stakeholder categories $\cdot$ Impact subcategories $\cdot$ Social indicators $\cdot$ PSILCA database $\cdot$ Electric vehicles $\cdot$ Social sustainability

Communicated by Marzia Traverso.

Ghada Bouillass

ghada.bouillass@mines-paristech.fr

Extended author information available on the last page of the article

\section{Introduction}

Developing sustainable mobility alternatives requires a big shift from the current car-based transport system, characterized by fossil oil dependency, high environmental impacts, 
health and safety issues in urban areas, and significant external costs for the society. Efforts are converging towards a better management of the impacts of products, technologies, and services on the environment and the society. For this reason, car manufacturers are increasingly looking to improve their management systems and to meet national and international regulations, such as EU requirements (The European Parliament and the Council 2014; EC 2016). As a result, significant reductions of environmental impacts are taking place thanks to improvements in the design phase. This includes lightweight materials development (Field et al. 2017), alternative fuels and powertrain efficiency increase (Dell et al. 2014a; 2014b; Harison 2018), materials recycling, and end-of-life vehicle recovery (Hu et al. 2017; Bobba et al. 2018; Harper et al. 2019).

Electric mobility has experienced a spectacular growth in the recent years, most notably between 2014 and 2019 where the annual average increase was 60\% (IEA 2020). Although electric vehicles can be favorable to achieve European Commission goals in terms of climate neutrality by 2050 (EC 2018a; 2018b), the associated social and socio-economic impacts are still unrevealed. Thus, the social sustainability of these technologies needs to be further assessed.

The availability and the efficiency of methods and tools for the identification, characterization, and monitoring of impacts play an important role in promoting environmental management schemes. Life cycle assessment (LCA) approaches have been widely used in the transport sector (Messagie 2014; Cox 2018; Cerdas et al. 2018). They allow the identification of environmental hotspots, processes with high environmental impacts, opportunities for future improvements, and communication on the environmental footprints. While assessment methods for the environmental dimension have significantly gained in maturity over the last years, the social impact assessment methods still lack a global consensus (Neugebauer 2016; Pérez-López et al. 2018; Zamagni 2019).

Corporate social responsibility (CSR) has gained importance in the automotive industry as a management tool for social sustainability (Russo-Spena et al. 2018). CSR disclosure does not refer to one specific methodology but rather stands on various normative references such as the International Labor Organization (ILO et al. 2019), Global Reporting Initiative standards (GRI 2011; 2016), International Integrated Reporting Council (IIRC) recommendations (IIRC 2014), the ISO 26000 standardization (ISO 26000 2010), and the UN Global Compact (UN-Global Compact et KPMG 2016). Despite the increasing number of CSR reports in the last years, a standardized framework for measuring social performance is still lacking (Russo-Spena et al. 2018). Hence, CSR domain is often contested and mainly perceived as a communication and marketing tool (Mahoney et al. 2013). Throughout a 4-year report-based study, Russo-Spena et al. (2018) have evaluated trends in CSR reports for 19 automotive companies. Such study demonstrated the need to introduce standardized social impact assessment approaches and highlighted the interest to consider harmonization of methods. In this regard, CSR disclosure could rely on social life cycle assessment (S-LCA).

\subsection{S-LCA methodological background}

S-LCA provides a standardized methodological framework that allows social and socio-economic impact measurements all along the products and services life cycles (UNEP 2020). The first guidelines for S-LCA of products, published by UNEP/SETAC (2009), valid until updated by the end of 2020, introduced five different stakeholder categories (workers, value chain actors, local community, consumers, and society). Each stakeholder category corresponds to one or a group of persons that are involved in the product system value chain (i.e., involved stakeholders) or susceptible of being affected by its related activities (i.e., affected stakeholders) throughout all life cycle stages. To evaluate potential social and socio-economic impacts, 31 social impact subcategories are described in a complementary set of methodological sheets for S-LCA published in 2013 (Benoît et al. 2013). Impact subcategories are social and socio-economic items or attributes that describe how each stakeholder category can be affected by the potential social and socio-economic impacts of the product system. These impact subcategories are evaluated through several inventory indicators for which quantitative, semi-quantitative, and qualitative data is collected.

Since the publication of S-LCA guidelines (UNEP/SETAC 2009) and the methodological sheets (Benoît et al. 2013), an increasing number of scientific articles on S-LCA have been published (Dreyer et al. 2010; Aparcana and Salhofer 2013; Neugebauer et al. 2014; Zanchi et al. 2018; Arvidsson 2019; Macombe 2019; Mancini et al. 2019; OsorioTejada et al. 2020). This demonstrates the need and interest of this approach to complete the environmental life cycle assessment and life cycle costing towards a better measurement of the sustainability of products and services. The UN Environment Program has therefore published the updated version of the S-LCA guidelines: "Guidelines for Social Life Cycle Assessment of Products and Organizations 2020" (UNEP 2020). The focus has been extended from products to also include an organizational scale (UNEP 2020). A new stakeholder category "Children" has been introduced and three impact subcategories have been proposed in the latest version of the guidelines to evaluate potential social and socio-economic impacts affecting this stakeholder category. The second version of S-LCA guidelines (UNEP 2020) now provides a description for each phase of S-LCA following the ISO14040-14044 framework (Finkbeiner et al. 2006). S-LCA is an iterative methodology, and each phase includes 
several—obligatory and optional—elements required for the implementation of S-LCA.

The main phases of S-LCA following the UNEP 2020 Guidelines are the following:

a

Goal and scope: This first phase of S-LCA covers the definition of the purpose of the study and the system boundaries, as well as the considered stakeholders and social impact subcategories. The goal and scope definition is considered a key phase of S-LCA (UNEP 2020). It should describe the main methodological pathways adopted such as the functional unit, the cutoff criteria, and the impact assessment method together with stakeholder groups and impact subcategories to be considered.

b Social life cycle inventory (S-LCI): All input and output flows are identified, as well as the social inventory indicators to be evaluated. For each considered product system, data is normalized for a given output process. Input/output flows can then be interlinked through an activity variable. Activity variables were first defined by Norris (2006) to reflect the relevance of social impact subcategories related to the process output. They allow describing the most intensive activities in a unit process and could therefore be used to prioritize data collection and quantify the considered social inventory indicators (UNEP 2020). The most common activity variable is "working hours" which refers to the number of hours spent to produce 1 USD output of the considered product system (Maister et al. 2020).

The two main S-LCA databases available are the Product Social Impact Assessment (PSILCA) database (Maister et al. 2020) and the Social Hotspot DataBase (SHDB) (Benoit-Norris et al. 2012). Both databases use the "working time" activity variable and can be used to build the targeted S-LCA model.

c Social life cycle impact assessment (S-LCIA): S-LCIA aims at measuring and understanding potential social and socio-economic impacts related to a product system. Potential social impacts are defined by UNEP (2020) as "the likely presence of a social impact, resulting from the activities/behaviors of organizations linked to the life cycle of the product or service and from the use of the product itself." Despite providing the main phases and elements to conduct a S-LCA, the first S-LCA guidelines (UNEP/SETAC 2009) did not include a clear consensus on the impact assessment method itself. This has led to the development of a large panel of social life cycle impact assessment (S-LCIA) approaches (Jørgensen et al. 2009; Dreyer et al. 2010; Rugani et al. 2012; Neugebauer et al.
2014; Jasinski et al. 2015; Arvidsson 2019; Karlewski et al. 2019; Gompf et al. 2020). S-LCIA approaches are classified into two main groups:

- Reference Scale Assessment (“Type I" or RS S-LCIA) focuses on the past or current social performance or social risks related to the behavior of the organizations involved in the product system along its life cycle stages.

- Impact Pathway Assessment (“Type II" or IP S-LCIA) assesses the consequences resulting from the product system (potential social impacts) through one or multiple characterization models that employ cause-effect relationships for evaluating impact categories that are comparable to E-LCA.

d Results interpretation: The interpretation of results is the final phase of S-LCA. It consists of reviewing all the previous phases and conducting a thorough analysis of S-LCA results. Following requirements of ISO 14044 (ISO 14044 2006), it should cover a completeness check, consistency check, sensitivity and data quality check, a materiality assessment and final conclusions, limitations, and recommendations (UNEP 2020). A materiality assessment is a process to select the most significant social issues regarding their impact on stakeholders or relevance to the business (UNEP 2020). It has also been defined and recommended by the Global Reporting Initiative (GRI 2011) and ISO 26000 (ISO26000 2010) to allow accounting for all relevant topics that might influence the assessment and decision-making process.

Among the different S-LCA studies, only a limited number targeted the automotive sector so far (Zanchi et al. 2018; 2020). These studies have mainly focused on developing social impact subcategories and inventory indicators based on the literature review analysis (Pastor et al. 2018; Karlewski et al. 2019; Gompf et al. 2020), and the domain of applicability and the main barriers for practical application of S-LCA (Zamagni et al. 2013; Zanchi et al. 2018). However, they provide very few elements to prioritize impact subcategories.

The definition of relevant social and socio-economic impact subcategories is a critical step in S-LCA. In fact, social relevance of the considered impact subcategories can influence result interpretation. Mobility relies on a complex stakeholders' network that could be either affected or involved in mobility supply chains, yet their perceptions are not integrated into the evaluation methods. Currently, only designers' and companies' perceptions are adopted in most cases (Zanchi et al. 2018). However, depending on the considered stakeholder perspective, the concerns and interests can vary significantly. Such restricted vision 
can lead to a partial representation of actual key social and socio-economic topics. The need to extend the involved stakeholders when prioritizing and evaluating social impact subcategories was also pointed by Karlewski et al. (2019). Following S-LCA guidelines (UNEP 2020), participatory approaches could be used for selecting the final set of indicators according to stakeholders' values, thus contributing to legitimating further the assessment and improving democratic representation.

To overcome the abovementioned limitations, we introduce a step-by-step S-LCA comprehensive framework, applicable to various product systems and sectors. Such S-LCA framework integrates a systematic novel approach for the identification and prioritization of relevant impact subcategories according to a multi-actor consultation process. The most relevant social and socio-economic impact subcategories are selected to perform the social evaluation and used to carry out a comprehensive analysis for the results interpretation by extending the scope of the materiality assessment to account for multiple concerned stakeholders.

We then implement the defined S-LCA framework for two mobility scenarios, corresponding to two different transportation technologies for passenger use in France: conventional and electric vehicles. This work could help S-LCA practitioners better integrate the perceptions of all affected and involved stakeholders for the assessment of social and socio-economic impact subcategories and contribute, thus, to conducting comprehensive analyses of S-LCA results.

\section{Materials and methods}

To facilitate the practical implementation of S-LCA, we have identified the need to formalize a comprehensive framework. We therefore propose here a step-by-step S-LCA framework based on the four main iterative phases as defined in the guidelines for S-LCA (UNEP 2020) consistent with ISO 14040 (Finkbeiner et al. 2006). Such framework is presented in Fig. 1. Our methodological contribution includes a systematic approach that adds two novel stages to the general S-LCA framework to improve the impact assessment and interpretation phases through the following: (1) a sectorial risk analysis for the identification of social and socio-economic impact subcategories and (2) a participatory approach implying all concerned stakeholders for their prioritization. In the following sections, we first describe the overall defined methodological framework that can be tailored for different products, technologies, and sectors. Then, we apply the framework for two different scenarios corresponding to electric and conventional transportation technologies, by describing each of the applied phases.
2.1 A step-by-step S-LCA comprehensive framework

\subsubsection{Goal and scope definition}

As mentioned in the S-LCA methodological background, the first phase of S-LCA covers the definition of the purpose of the study and system boundaries, as well as the considered stakeholders and social impact subcategories. It should describe the main methodological pathways adopted such as the functional unit, the cutoff criteria, and the impact assessment method (UNEP 2020).

In this study, elementary flows and process activities are used to identify directly and indirectly related stakeholders. The listed stakeholder categories can be then prioritized following different criteria (UNEP 2020). As shown in Fig. 1, one of the key features provided by this work is the introduction of specific steps in the first phase of S-LCA for the identification and prioritization of social and socioeconomic impact subcategories. The proposed two-stage approach for their identification and prioritization is presented in Fig. 2. This approach can be adopted to select the most relevant topics for the evaluation and interpretation phases. It could be applied for different product systems and sectors. The designed approach for the identification and prioritization is to be conducted through the following steps:

Stage 1: Identification of relevant impact subcategories following a sectorial social risk analysis A sectorial risk analysis is proposed to identify social hotspots and topics covering all life cycle stages and stakeholder categories previously defined. The aim of this first stage is to complete the UNEP (2020) recommended list of impact subcategories through an extensive identification of social and socio-economic topics that are related to the studied sector. The identification stage involves the analysis of specific positive and negative social topics of the product system under investigation. It should account for the system boundaries and the related process activities together with their geographical locations. The list of social impact subcategories proposed by the S-LCA guidelines (UNEP 2020) should be refined by (i) the analysis of the reports of social externalities studies (i.e., regulatory texts, ILO conventions, normative references), and (ii) scientific publications dealing with S-LCA, social sustainability, and social assessment studies of the considered product system. The complete procedure is further explained in detail for the considered mobility scenarios.

The recommended list of impact subcategories by the S-LCA updated guidelines is then adapted by adding new sector-dependent social and socio-economic impact subcategories. The representativeness of the corresponding inventory indicators is verified to check whether they covered the 


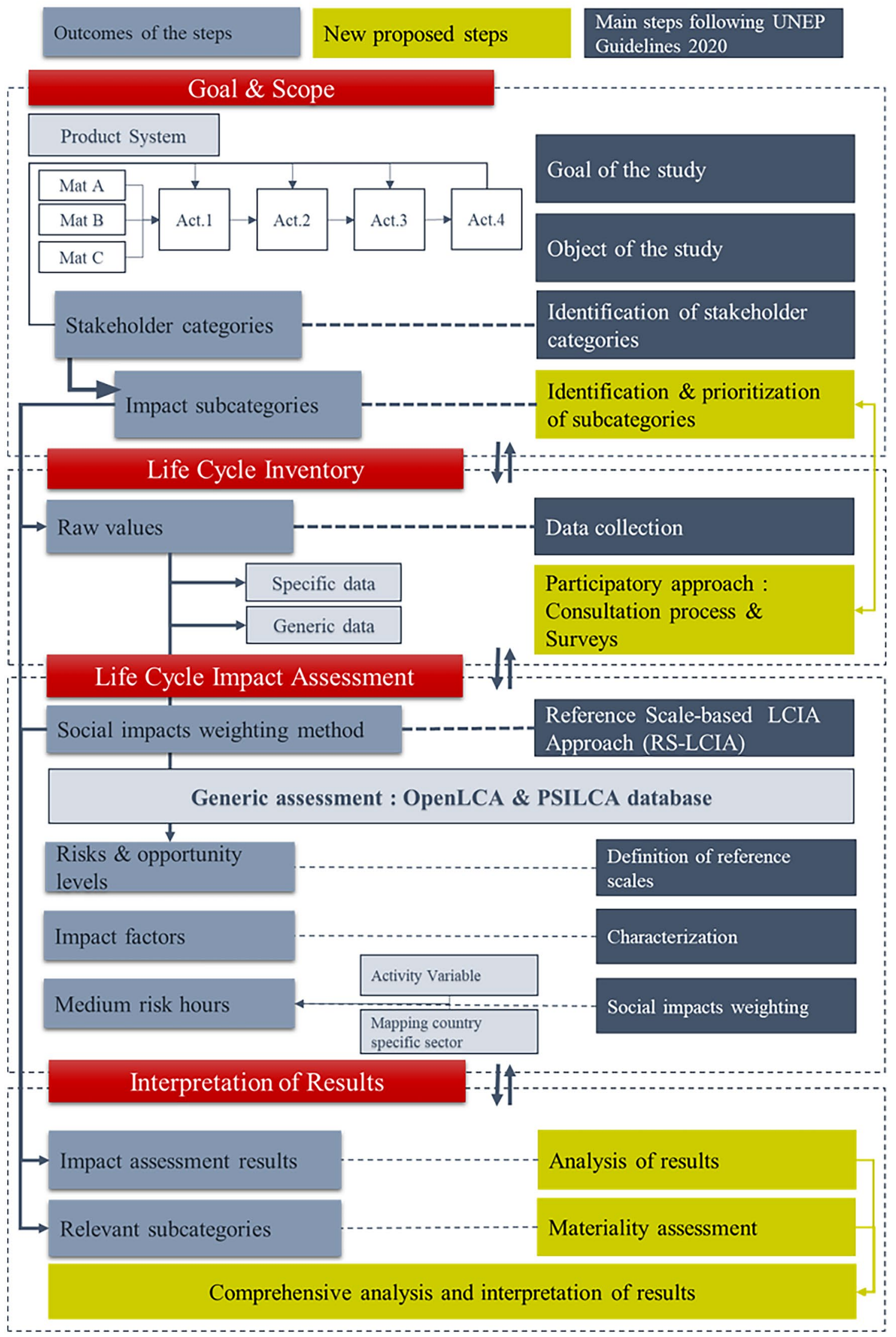

Fig. 1 Comprehensive methodological framework proposed in this work - adapted from RS-LCIA (UNEP 2020) 


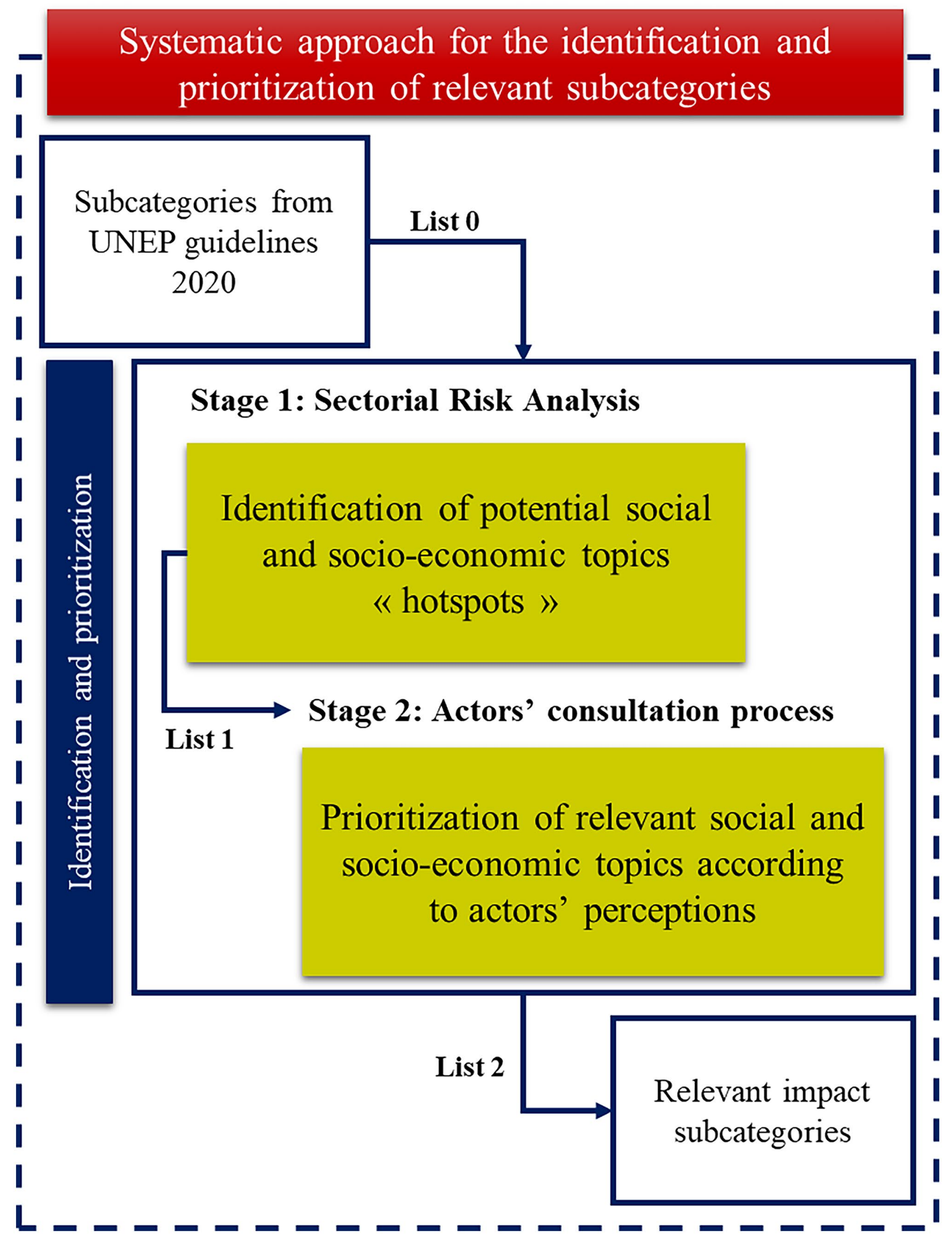

Fig. 2 Developed approach for the identification and prioritization of relevant S-LCA subcategories 
identified social and socio-economic topics or not. If not, new impact subcategories are suggested.

\section{Stage 2: Actors' consultation process for the prioritization of} relevant impact subcategories After the identification of the complete list of impact subcategories in the previous stage, a participatory approach is designed to gather information about their social significance for directly affected and involved stakeholders within the life cycle of the product system, as defined by the S-LCA guidelines (UNEP 2020). Limitations may prevent S-LCA practitioners to consult some of the directly affected and involved stakeholders (for example, workers or local communities in the extraction or end of life phases). In this case, external stakeholders not directly linked to the life cycle of the product system, namely external concerned stakeholders, can be consulted instead according to their relevance. Such relevance can be determined following their level of concern, likeliness of representativeness of affected and/or involved stakeholder interests, awareness, and level of influence on decision making. Consequently, there are two different levels of consulted actors: directly affected and involved stakeholders whenever they can be consulted, and external concerned stakeholders for all other cases. As a result, the survey can include one or more questionnaires according to the type of consulted actor being targeted and the goal and scope of the study.

To perform the prioritization, surveys are undertaken, implying all consulted actors, who are asked to order the list of impact subcategories according to the importance they assign to each one in an online survey. Other tools to perform these surveys could be used, depending on their suitability for the goal and scope of the study and the type of data to be collected. For example, individual interviews can be used as a main data source if qualitative information is needed in the study. The addressed questions should describe positive and negative social and socio-economic topics that could have an impact on any of the five directly affected and involved stakeholders. The aim is to consider the increasing concern of all stakeholders about social and socio-economic topics associated with their decisions and understand how sustainability aspects could guide their choices. Social significance of the impact subcategories to be considered should not be restricted on a single stakeholder perspective. Distinctive characteristics of life cycle stages and the corresponding geographical area should also be taken into consideration in the questions assuming that the importance of impact subcategories can vary depending on the scope of the study. Individual interviews are highly recommended, whenever possible, to complete the online surveys. This is particularly important when closed-ended questions are addressed. Depending on the studied product system, several adjustments could be made, and the designed approach could be customized to cover special features related to the considered sector and actors to be consulted. We later explain how this designed participatory approach is applied to electric and conventional vehicle technologies.

\subsubsection{Definition and structure of the social life cycle inventory $(\mathrm{S}-\mathrm{LCl})$}

As abovementioned, this phase aims at collecting generic and specific data to perform the evaluation phase. Modeling product systems from a S-LCA perspective requires the use of multiple data sources that could be either generic or specific. Primary data is needed to determine amounts of input flows, social inventory indicators and corresponding risk or opportunities levels, and finally the activity variables that allow interlinking data for various product systems.

Although site-specific data accessibility is often a limiting factor when conducting the S-LCI phase, it is highly recommended in this phase (UNEP 2020) to cover social and socio-economic aspects related to a specific production site or a case study that cannot be fully measured with generic databases. Specific data is therefore needed to complete the results of these generic databases and thus enhance their representativeness. In addition, specific data in this study is collected to select relevant social impact subcategories as explained in the prioritization stage of the proposed framework.

\subsubsection{Social life cycle impact assessment (S-LCIA) definition}

The S-LCIA phase is conducted in this study according to "Type I" impact assessment approaches, namely "Reference Scale-based Social Impact Assessment" (RS S-LCIA). In fact, the current development of characterization models within the "Impact Pathway Social Life Cycle Impact Assessment" (IP SLCIA) is limited to potential social and socio-economic impacts for a single stakeholder category, the workers, and for a very restricted number of impact subcategories. RS-LCIA approaches enable the assessment of all stakeholder groups and their related impact subcategories, which makes them more compatible with the multi-actor perspective introduced in this work. Moreover, the main S-LCA databases are in line with RS-LCIA, which are also a key support for this study. Indeed, S-LCA generic databases measure social risks at country and sector data levels. Besides the methodological sheets, the Handbook for Product Social Impact Assessment (PSIA) (Fontes et al. 2016; Goedkoop et al. 2020a; 2020b) is an important basis for type I assessment approaches. The S-LCIA phase covers the definition of reference scales that are used to evaluate each of the social inventory indicators considered for the product system. Performance reference points (PRP) are also determined to allow estimating social risk or performance levels comparing to international standards, local legislations, 
and organizations best practices. In the case of generic database use, reference scale and PRP are provided for each social inventory indicator. According to the framework defined in this work, social and socio-economic impact subcategories that are perceived as the most relevant following the prioritization are used to perform the S-LCIA phase. Social inventory indicators, performance scales, and PRP are attributed to the selected social and socio-economic subcategories. The calculation is performed following the characterization method chosen for the study. We further explain how this phase was conducted using PSILCA generic database with an application to electric and conventional transportation technologies.

\subsubsection{A comprehensive analysis for social life cycle interpretation}

To ensure a comprehensiveness analysis of the results, this study integrates a participatory approach to social life cycle interpretation. In this regard, perceptions of the different consulted actors on the social significance are introduced in this paper as a novelty to select the most relevant impact subcategories to be further evaluated through the S-LCIA phase. Involving various affected and concerned stakeholders should help enhance the materiality assessment by extending the scope to fully consider the divergence of interests and objectives that can occur between the various stakeholders. Such work should improve representativeness of the materiality assessment that usually reflects solely the organization's perspective and does not take into consideration the points of view of other stakeholders about the economic, environmental, and social topics that could substantially affect them, directly or indirectly.

Throughout this study, we aim at overcoming this limitation by using a qualitative ranking to prioritize social and socio-economic impact subcategories according to various actors' perceptions. Results from the consultation process could therefore be used to discuss the social significance of the social and socio-economic impact subcategories and to compare the different points of view. Such approach enables extending the scope of the interpretation phase and considering stakeholders' expectations and their increasing concern on social and socio-economic topics.

\subsection{Implementation of the defined S-LCA methodological framework for mobility scenarios}

\subsubsection{Goal and scope definition for mobility scenarios}

The goal of the implementation of S-LCA framework in this work is to evaluate the social risks associated with electric vehicle transportation technologies in comparison with the conventional ones. The function of the evaluated system is to ensure the transport of passengers in France for a midsized vehicle. We consider 1 USD output of the product system for the input process modeling. The system boundaries in this study are presented in Fig. 3. We analyze impact subcategories related to the manufacturing, distribution, use,

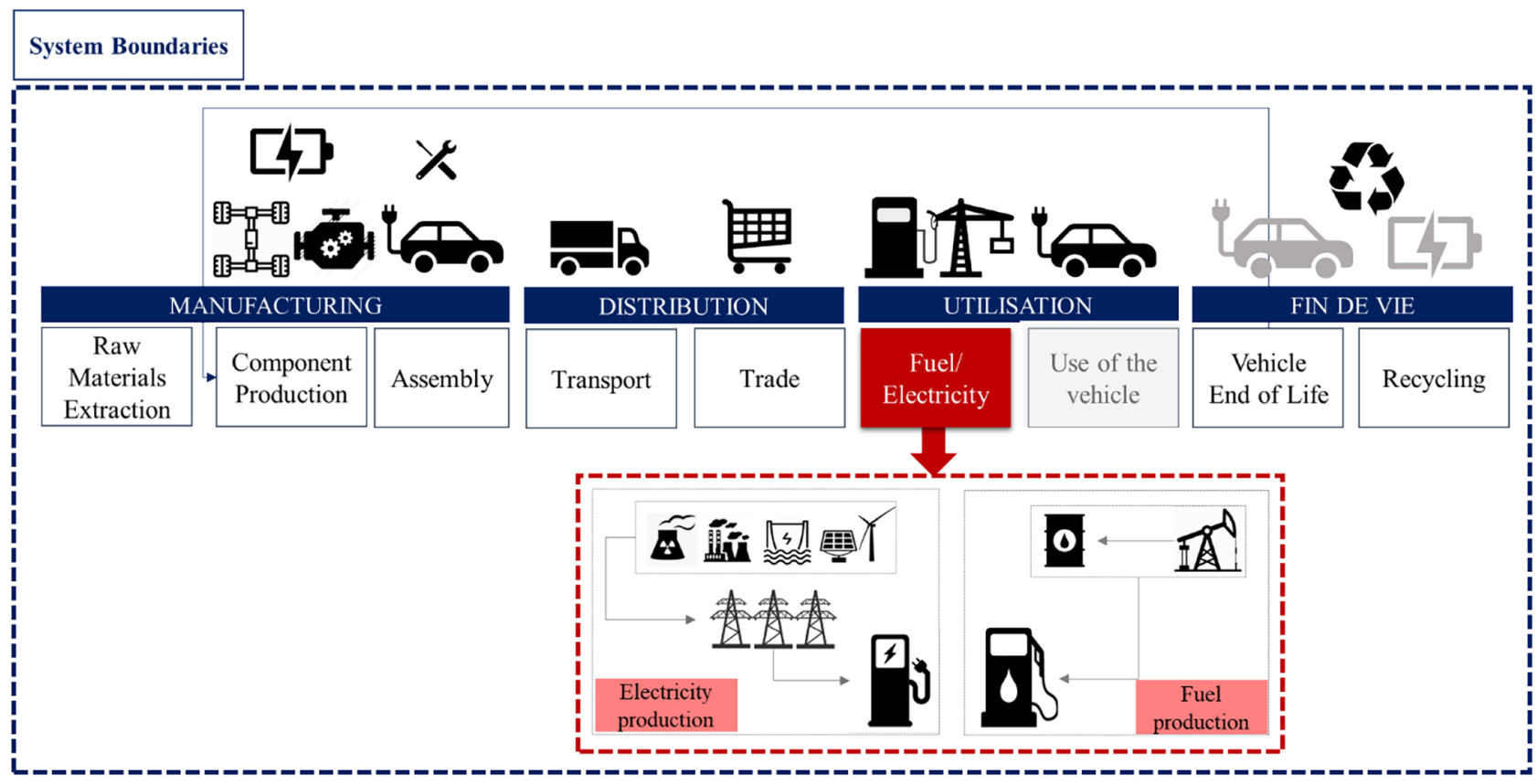

Fig. 3 System boundaries considered in this study: "Cradle-to-Grave" and "Well-to-Wheel" 
and end of life of the vehicles. For both electric and conventional vehicles, the main components and raw materials are identified (e.g., battery production and powertrains) together with the raw materials and their corresponding geographical location (lithium, cobalt, steel, etc.) from previous sustainability assessment studies (Hosseinijou et al. 2014; Bobba et al. 2018; Mancini et al. 2019). In addition, two energy production pathways are assessed in this study for the vehicles' power sources, namely electricity and fuel production in France. In fact, the analysis of transport energy sources is increasingly required to complete environmental and economic assessments due to high use of fossil fuels and their associated risks on resources depletion and as a result the degradation of safe and healthy living conditions (Hoque et al. 2020).

The defined life cycle stages are assessed following the sector/country social risks; therefore, the input-output flows are identified to reflect the share of each process activity into the final product output rather than physical flow connections, as done in environmental LCA. Geographical locations of each process activity are identified to allow a representative coverage of the associated impact subcategories considered in the assessment.

For the identification of stakeholders, we considered the five stakeholder categories originally recommended by the UNEP/SETAC guidelines in the 2009 version, namely, workers, value chain actors, society, local communities, and consumers. In fact, UNEP (2020) S-LCA revised guidelines introduced "children" as a new stakeholder category and additional impact subcategories for other stakeholders. However, these were not included in the current study due to the lack of indicators and data for their analysis through the existing S-LCA databases. In this regard, this study focused on the first UNEP/SETAC stakeholder categories and impact subcategories (Benoît et al. 2013). Moreover, in this study, the term "users" refers to "consumers," "customers," or "passengers."

We further identified mobility-related stakeholders through the analysis of several studies for stakeholders' identification and mapping in mobility (Zambre 2015; Jones et al. 2015; Le Pira et al. 2016; Harrington et al. 2016; Garrido Fernández 2018; Imre Keseru et al. 2018; Mancini and Sala 2018). These have addressed direct relations occurring between stakeholders and the studied product system and indirect relations resulting from interactions with other related sectors such as mineral extraction (Mancini eand Sala 2018; OECD 2021), manufacturing activities, use phase (Spickermann et al. 2014; Lindenau and Böhler-Baedeker 2014; Kostiainen and Tuominen 2019; Esztergár-Kiss and Tettamanti 2019; Kougias et al. 2020; Ludovico et al. 2020; Bjørgenet al. 2021), and final disposal of transportation technologies as defined within the system boundaries. The list of identified stakeholders and their definition together with the type of the occurring interaction are provided in the supporting information, $\mathrm{S} 1$.

Users' stakeholder category is the least represented stakeholder category in S-LCA studies related to the mobility sector (Petti et al. 2016; Osorio-Tejada et al. 2020) as social risks are usually evaluated directly through organization performance. In this study, we do consider users as a key stakeholder due to the significant impact they have on social acceptability of the final transportation technology (L'Hostis et al. 2016; Chalkia et al. 2017). We therefore identified a new set of social and socio-economic topics related to users' stakeholder category particularly suitable for the mobility sector. We also integrated their perception in the prioritization stage to identify relevant impact subcategories and thus their expectations and concerns in terms of sustainable mobility alternatives. However, the evaluation of userrelated social inventory indicators was not possible as no correlation can be made with the activity variable used in this study and no social inventory indicators are available in generic databases (Goedkoop et al. 2020b). Following the approach designed for the implementation of S-LCA explained in Sect. 2.2.1, the identification and prioritization of relevant impact subcategories were conducted following two stages:

Stage 1: Identification of impact subcategories following a sectorial social risk analysis applied to mobility scenarios To perform the identification stage, we used UNEP/SETAC methodological sheets (Benoît et al. 2013) and the PSIA handbook (Goedkoop et al. 2020b) as a basis. As explained in the methodology description (Sect. 2.2.1), we analyzed a total number of 223 studies on social externalities, transportation regulations, and standards to identify potential social and socio-economic topics as well as scientific publications dealing with these issues. A thorough literature review was therefore conducted by using academic databases allowing the identification of peer-reviewed scientific publications. The used keywords for the review were "S-LCA," "Social LCA," "social sustainability," "electric vehicles," "mobility," "transport," "mining," "extraction," "social aspects," "social assessment." We identified 68 scientific publications that covered various social and socio-economic topics for different life cycle stages of vehicles and related supply chains. These publications addressed two scales: micro level covering different technologies, materials, and components such as battery and powertrain production (Leurent and Windisch 2015; Noel et al. 2018; Onat et al. 2016; Lopez-Arboleda et al. 2019; Smaragdakis et al. 2020; Patil and Khairnar 2021; Omahne et al. 2021) and macro level addressing global social impacts of market electrification, policies, and other sectors that are related to transport (Azapagic 2004; Zhang et al. 2015; Kamenopoulos et al. 2016; Litmanen et al. 2016; Zimmer et al. 2017; Mancini 
and Sala 2018; Orozco 2018; Pastor et al. 2018; Schlör et al. 2018; Zambrano-Gutiérrez et al. 2018; Aznar-Sánchez et al. 2019). In addition, we have collected a total number of 155 official reports from the International Labor Office (ILO), OECD, World Bank, and the JRC reports. An iterative approach was followed to identify stakeholders and the associated social and socio-economic topics covered by these studies. We have extended the scope to cover raw materials extraction and mining activities (OECD 2016; 2019b; 2019a; 2021; World Bank 2006; 2010; 2020). Among 91 different ILO studies, 46 did not concern the scope of our research (e.g., railway transport, aviation). The selected 45 studies focused on "road transport" and "transport equipment manufacturing" (Turnbull 2013; International Labour Office 2010; 2020; 2015b; 2015a; 2016; 2018), "road infrastructures" (Johannessen 2009; World Bank 2010), "basic metals production" (International Labour Office 2001; 2005), "oil and gas industry" (Graham 2010; International Labour Office 2015c), and "mining activities" (Walle 2001; ILO 2002; Loayza and Rigolini 2016; Coderre-Proulx et al. 2016; International Labour Office 2019b; 2019a; Hilson and Maconachie 2020; International Labour Office 2021; McQuilken and Perks 2021). These studies were analyzed to identify relevant positive and negative social and socio-economic topics for transport. The most discussed social and socio-economic issues were identified, such as "health and safety," "decent working conditions," "employment," "child labor," "gender equity - women employment," and "migrant workers." These described mostly topics related to workers and local communities. Furthermore, we used Russo-Spena et al. (2018) study that analyzed the most discussed social and socio-economic topics in 19 different automotive CSR reports.

To cover users-related social and socio-economic impact subcategories, we have considered the UNEP 2020 Guidelines list of impact subcategories. However, these do not cover all the social and socio-economic topics that are related to transport technologies, mobility services, and transport infrastructures. We have therefore defined new mobility-related impact subcategories for users' stakeholder. To do so, normative references and regulations at the European scale were gathered (CNIL 2016; 2018; UE and CNIL 2018; EC 2019) as well as 27 different scientific publications that focused mainly on users' stakeholder category. Among the different S-LCA studies targeting transport sector, only few considered users. Gompf et al. (2020) have defined a set of indicators for mobility services to be introduced to S-LCA based on various social assessment for urban mobility. Moreover, a project from the European commission (European Commission 2020) came up with the definition of a core set of 14 different sustainable urban mobility indicators for users. These indicators were used to support the definition of users' impact subcategories allowing the comparison of the defined mobility scenarios and more representativeness of the actual social and socio-economic impacts. The complete list of social and socio-economic topics is presented and discussed in the results section.

Stage 2: Actors' consultation process for the prioritization of relevant impact subcategories applied to mobility scenarios According to the designed participatory approach in this work, we developed three sets of surveys according to three different types of consulted actors: users (survey 1 ), worker unions (survey 2), and industrial, academic, and public actors (survey 3). Table 1 presents the consulted actors and the affected and/or involved stakeholders for which impact subcategories describe the positive and negative potential social topics to prioritize. All the asked questions in the three online surveys are available in the supporting information, S2. A total number of 70 different respondents were consulted in France to gather the information on impact subcategory prioritization.

Survey (1) covered in total eight main questions that addressed two main elements according to a user perspective: (1) identification of the most relevant impact subcategories affecting users directly by both electric and conventional transportation technologies, (2) identification of the

Table 1 The designed multi-actor consultation process for the electric mobility case study, survey types, and the corresponding actors

\begin{tabular}{|c|c|c|c|c|c|}
\hline \multirow{2}{*}{$\begin{array}{l}\text { Involved and/or affected stakeholders (recom- } \\
\text { mended by UNEP/SETAC guidelines) }\end{array}$} & \multicolumn{5}{|c|}{ Consulted actors (affected and/or involved stakeholders + external concerned stakeholders) } \\
\hline & Users & Worker unions & Public actors & $\begin{array}{l}\text { Industrial } \\
\text { actors }\end{array}$ & $\begin{array}{l}\text { Academic } \\
\text { actors }\end{array}$ \\
\hline Users & $\mathrm{X}$ & & $\mathrm{X}$ & $\mathrm{X}$ & $\mathrm{X}$ \\
\hline Workers & $\mathrm{X}$ & $\mathrm{X}$ & $\mathrm{X}$ & $\mathrm{X}$ & $\mathrm{X}$ \\
\hline Local communities & $\mathrm{X}$ & & $\mathrm{X}$ & $\mathrm{X}$ & $\mathrm{X}$ \\
\hline Value chain actors & & & $\mathrm{X}$ & $\mathrm{X}$ & $\mathrm{X}$ \\
\hline \multirow[t]{2}{*}{ Society } & & & $\mathrm{X}$ & $\mathrm{X}$ & $\mathrm{X}$ \\
\hline & Survey 1 & Survey 2 & Survey 3 & & \\
\hline
\end{tabular}


most important impact subcategories related to workers and local communities' stakeholder categories in the manufacturing stage. The aim was to understand potential effects of social and socio-economic topics on their choices in terms of mobility and their concern related to social sustainability aspects of emergent electric vehicles technologies.

Survey (2) described potential impact subcategories for workers according to worker unions' perspective. Direct consultation of workers appeared to be quite challenging; we therefore selected worker unions. They represented three types of entities, namely, worker unions in vehicle's production sites in France, worker unions from VTC (the French abbreviation for chauffeur-driven private cars), and worker unions from public transportation services in France. These actors were asked to prioritize the direct social and socioeconomic topics associated to workers in France through an online survey and individual interviews. The survey covered seven main questions. They also were asked to describe, for each subcategory, the risk level according to the geographical area where the activity is located.

Survey (3) was addressed to public authorities, and academic and industrial actors according to their roles, respectively, as decision-makers, researchers, experts, and developers of products and technologies. The online survey entailed thirteen questions describing social and socio-economic topics associated to all involved and/or affected stakeholders (users, worker, local communities, value chain actors, and society). The aim was to understand how each impact subcategory was perceived in terms of its significance in the assessment, relevance to business, and its importance in the decision-making process.

As stated before, multiple adjustments might be required to the designed consultation process. In the current case study, a focus was made on potential social and socio-economic impacts related to the electro-mobility shift (i.e., "In the context of an electric mobility transition, what would be the social and socio-economic issues that you are most concerned about?"). The questions addressed mainly three different aspects, which can also be considered part of the assumptions we fixed in this work:

- The geographical location: We considered two cases for the geographical location, namely, outside Europe and inside France.

- Transportation technologies: We considered both electric and conventional transportation technologies to allow the comparison of social significance of impact subcategories in both cases.

- The type of mobility service: We distinguished personal, shared mobility, and public transportation. Indeed, users were asked to prioritize social and socio-economic topics following these three types of transportation modes. However, these results were not of importance to the objective of this work as the mobility services were not considered within the scope of the present study.

\subsubsection{Definition and structure of the social life cycle inventory for mobility scenarios}

In this study, we used the PSILCA database to obtain data on social inventory indicators. PSILCA database uses a MultiRegional Input/Output (MRIO) (Mattila 2018) model from the EORA database (Lenzen et al. 2013). EORA covers economy of global supply chains on an industrial sector basis and uses monetary flows to link different sectors and processes. PSILCA is a country-specific sector (CSS) database. It covers 189 different countries for which a wide range of sectors are attributed (around 15,000 different sectors in total). Both inputs (materials and products provided by other sectors) and outputs (generated products) of a CSS are expressed in USD (Maister et al. 2020). The version 2 of PSILCA database, uwsed in this work, provides 65 qualitative and quantitative social indicators that address a set of 19 impact subcategories classified into 4 stakeholders, namely, workers, value chain actors, local communities, and society. Data is gathered from several international references such as the ILO (International Labor Organization et al. 2019), the World Bank (World Bank 2017) and the World Health Organization (WHO 2015), and United Nations (United Nations 2012). Additional public and private databases are used, together with site-specific investigations carried out by GreenDelta (Maister et al. 2020) to provide data on risk levels and activity variables.

In this study, inputs of each evaluated process were identified based on the defined system boundaries. To do so, we looked in PSILCA database for processes that corresponded to the vehicle life cycle stages defined in Fig. 3. Input materials of the evaluated products and their amounts were collected from ecoinvent database (Del Duce et al. 2016) and GREET_2: vehicle_Inputs (Keoleian et al. 2012). The input processes were connected through monetary values (in USD) corresponding to their contributions into the output of the evaluated product system. In case of lacking data, amounts of input process activities were estimated through other similar existing processes in the PSILCA database.

The activity variable used in this study to measure process output and reflect the impact share (relative significance) of each unit process related to the product system was "working time." Worker hours are related to 1 USD of process (or sector) output and are calculated in PSILCA through the following Eqs. (1) and (2) (Maister et al. 2020): 
Worker hours $=\frac{\text { Unit labor costs }}{\text { Mean hourly labor cost (per employee) }}$

With: of $1 \mathrm{E}-5$ was applied for the definition of the product systems, according to the features of the used version of the PSILCA database. The assessment method implemented in the PSILCA database is the "social impacts weighting

Unit labor costs $=\frac{\text { Compensation of employees (in USD per country }- \text { specific sector and year) }}{\text { Gross output (in USD per country }- \text { sector and year) }}$

However, the provided values of the worker hours were calculated for PSILCA database and cannot be sourced on external published references. The amounts of worker hours have been selected for the corresponding processes used in this study to calculate the working time activity variable, following Eq. (3), for both evaluated transportation technologies:

working time $=$ worker hours per 1 USD product output

* total price of the product $*$ share of labor costs

Vehicle labor costs are uncertain and dependent on the considered technology. Hybrid electric vehicles (HEV) seem to have higher labor costs than battery electric vehicles (BEV), while no clear distinctions between BEV and internal combustion engine vehicles (ICEV) are found. We have used a share of labor costs of $10 \%$ of the total cost of vehicle manufacturing based on König et al. (2021). Total prices of vehicles were taken for the most adopted urban electric vehicles (EV) and ICEV technologies in France, corresponding respectively to $39,120.99$ USD (Renault 2020) and 19,229.92 USD (Peugeot 2020). The worker hours per 1 USD product output provided for "manufacture of motor vehicles" in France by PSILCA is $0.002481 \mathrm{~h} / \mathrm{USD}$. This value has been used to perform the calculation of the working time. Hence, the used working times for both scenarios are $9.71 \mathrm{~h}$ for $\mathrm{EV}$ and $4.77 \mathrm{~h}$ for ICEV.

These values are attributed to each of the selected social inventory indicators in the S-LCIA phase. The working time activity variable originally refers to the workers' stakeholder category group and is less compatible with other stakeholder groups. Other activity variables, such as the value added that consists of the amount of the added value created in each process activity, and other paths allowing direct quantification of inventory indicators without need of activity variables are currently under development to cover the various stakeholder groups (Cirothet al. 2019).

\subsubsection{Social life cycle impact assessment for mobility scenarios}

The S-LCIA phase for electric and conventional transportation technologies was performed using OpenLCA software (1.9) and version 2 of PSILCA database. A cutoff criterion method." Social risks related to all involved processes in the life cycle of the product system are aggregated by price (inputs), working time (activity variable), and various impact factors (characterization factors), which enables expressing social assessment results in [medium risk hours]. Table 2 presents the selected subcategories and their corresponding inventory indicators as suggested byPSILCA database. The employed reference scales in PSILCA distinguish risk levels that vary from "very low risk" to "very high risk," and opportunity levels that vary from "low opportunity" to "high opportunity" that allow S-LCA practitioners to account for the positive aspects. Within each impact subcategory, social and opportunity levels are translated in a quantitative metric through an impact factor (Maister et al. 2020). All subcategories and their corresponding inventory indicators, together with the equivalencies between quantitative metrics and risk levels, can be found in PSILCA database documentation (Maister et al. 2020).

The considered life cycle stages and their corresponding process activities selected from PSILCA database for both electric and conventional transportation technologies are presented in supporting information, S3. We have selected the existing process activities that cover vehicle production, battery and powertrain production, raw material manufacturing, electricity, and fuel production and those related to recycling. For some process activities, multiple locations were identified and used to allow the comparison of social and socio-economic topics and the identification of social hotspots depending on the geographical context. Energy processes linked to vehicle operation in France were also analyzed for both electricity and fuel production for the French context.

\subsubsection{Comprehensive analysis for social life cycle interpretation for mobility scenarios}

In this phase, results of the prioritization of impact subcategories and those selected for the S-LCIA evaluation phase are analyzed. Table 2 presents the selected impact subcategories and the inventory indicators used from the PSILCA database for the evaluation. In this study, usersrelated impact subcategories for mobility scenarios are defined and prioritized following the proposed participatory approach. In addition, social risks associated with electric 
Table 2 Considered subcategories and their corresponding inventory indicators in PSILCA (Maister et al. 2020)

\begin{tabular}{|c|c|c|c|}
\hline Stakeholder categories & Selected impact subcategories & $\begin{array}{l}\text { Inventory indicators used through } \\
\text { PSILCA database }\end{array}$ & $\begin{array}{l}\text { Definition of the indicators and units of } \\
\text { measurement }\end{array}$ \\
\hline \multirow[t]{3}{*}{ Workers } & Child labor & $\begin{array}{l}\text { Children employment, total } \\
\text { [CE medium risk h] }\end{array}$ & Percentage of all children ages $7-14$ \\
\hline & Forced labor & $\begin{array}{l}\text { Goods produced by forced labor } \\
\text { [GFL medium risk h] }\end{array}$ & $\begin{array}{l}\text { Number of goods produced by forced } \\
\text { labor in the sector }\end{array}$ \\
\hline & Health and safety & $\begin{array}{l}\text { Rate of fatal accidents at workplace } \\
\text { [FA medium risk h] } \\
\text { Rate of non-fatal accidents at work- } \\
\text { place [NFA medium risk h] }\end{array}$ & $\begin{array}{l}\text { Number of fatal accidents per } 100,000 \\
\text { employees and year } \\
\text { Number of non-fatal accidents per } \\
100,000 \text { employees and year }\end{array}$ \\
\hline \multirow[t]{3}{*}{ Local communities } & Safe and healthy living conditions & $\begin{array}{l}\text { Drinking water coverage } \\
\text { [DW medium risk } \mathbf{h}] \\
\text { Pollution level of the country } \\
{[\mathbf{P} \text { medium risk } \mathbf{h}]}\end{array}$ & $\begin{array}{l}\text { Percentage of the population with } \\
\text { access to drinking water } \\
\text { Pollution Index based on perceptions }\end{array}$ \\
\hline & Local employment & $\begin{array}{l}\text { Unemployment rate in the country } \\
\text { [LC medium risk h] }\end{array}$ & Percentage of the population \\
\hline & Delocalization and migration & $\begin{array}{l}\text { Net migration rate } \\
{[\mathbf{N M} \text { medium risk } \mathbf{h}]}\end{array}$ & $\begin{array}{l}\text { Difference between number of emi- } \\
\text { grants and immigrants during a given } \\
\text { year per } 1000 \text { inhabitants }\end{array}$ \\
\hline \multirow[t]{2}{*}{ Value chain actors } & Promotion of social responsibility & $\begin{array}{l}\text { Membership in an initiative that } \\
\text { promotes social responsibility along } \\
\text { the supply chain } \\
\text { [PSR medium risk h] }\end{array}$ & $\begin{array}{l}\text { Number of companies involved in CSR } \\
\text { along the supply chain }\end{array}$ \\
\hline & Fair competition & $\begin{array}{l}\text { Anti-competitive behavior or violation } \\
\text { of anti-trust and monopoly legisla- } \\
\text { tion } \\
\text { [AC medium risk h] }\end{array}$ & $\begin{array}{l}\text { Number of violations per } 10,000 \\
\text { employees in the sector }\end{array}$ \\
\hline Society & $\begin{array}{l}\text { Contribution to economic develop- } \\
\text { ment }\end{array}$ & $\begin{array}{l}\text { Contribution of the sector to the } \\
\text { economic development } \\
\text { [CED medium risk h] }\end{array}$ & $\begin{array}{l}\text { Shares of breakdown of GDP/value } \\
\text { added at current prices in percent; } \\
\text { if value is derived from the Mining } \\
\text { contribution index it expresses the } \\
\text { metallic mineral and coal production } \\
\text { value } 2014 \text { (as \% of GDP) }\end{array}$ \\
\hline
\end{tabular}

and conventional vehicle supply chains are analyzed for four stakeholder categories, namely workers, local communities, value chain actors, and society, through a generic assessment. A total number of 9 impact subcategories and 11 social inventory indicators are discussed. Further results of the prioritization phase, together with additional impact assessment results for value chain actors and society's impact subcategories, are provided in the supporting information, S4 and S5.

\section{Results and discussion}

\subsection{Results from the identification and prioritization of impact subcategories for mobility scenarios}

The designed approach within S-LCA framework provides (1) the identification of a new set of impact subcategories for users related to mobility and (2) the prioritization of all impact subcategories following various actors' perceptions.
Stage 1: Identified impact subcategories following a sectorial social risk analysis for mobility scenarios The sector-based risk analysis has enabled the definition of a first set of social and socio-economic subcategories related to five stakeholder categories that were subsequently ranked through the consultation process designed within the prioritization stage. The defined impact subcategories mainly arise from S-LCA guidelines (UNEP 2020) and PSIA handbook (Goedkoop et al. 2020b). More specific impact subcategories are added, especially related to the users' stakeholder category, since for other stakeholder groups the identification stage showed that the topics are sufficiently covered by the indicators proposed by the S-LCA guidelines. The new identified impact subcategories for users are presented in Table 3. These include safety issues (e.g., road accidents, sexual harassment, and insecurity feelings), health and comfort (e.g., vibrations, noises, thermal comfort), users' privacy (consumers' personal data uses and privacy management by vehicles' manufacturers and mobility operators), communication system (including transparency, end of life responsibility, mobility service information quality, etc.), availability and 


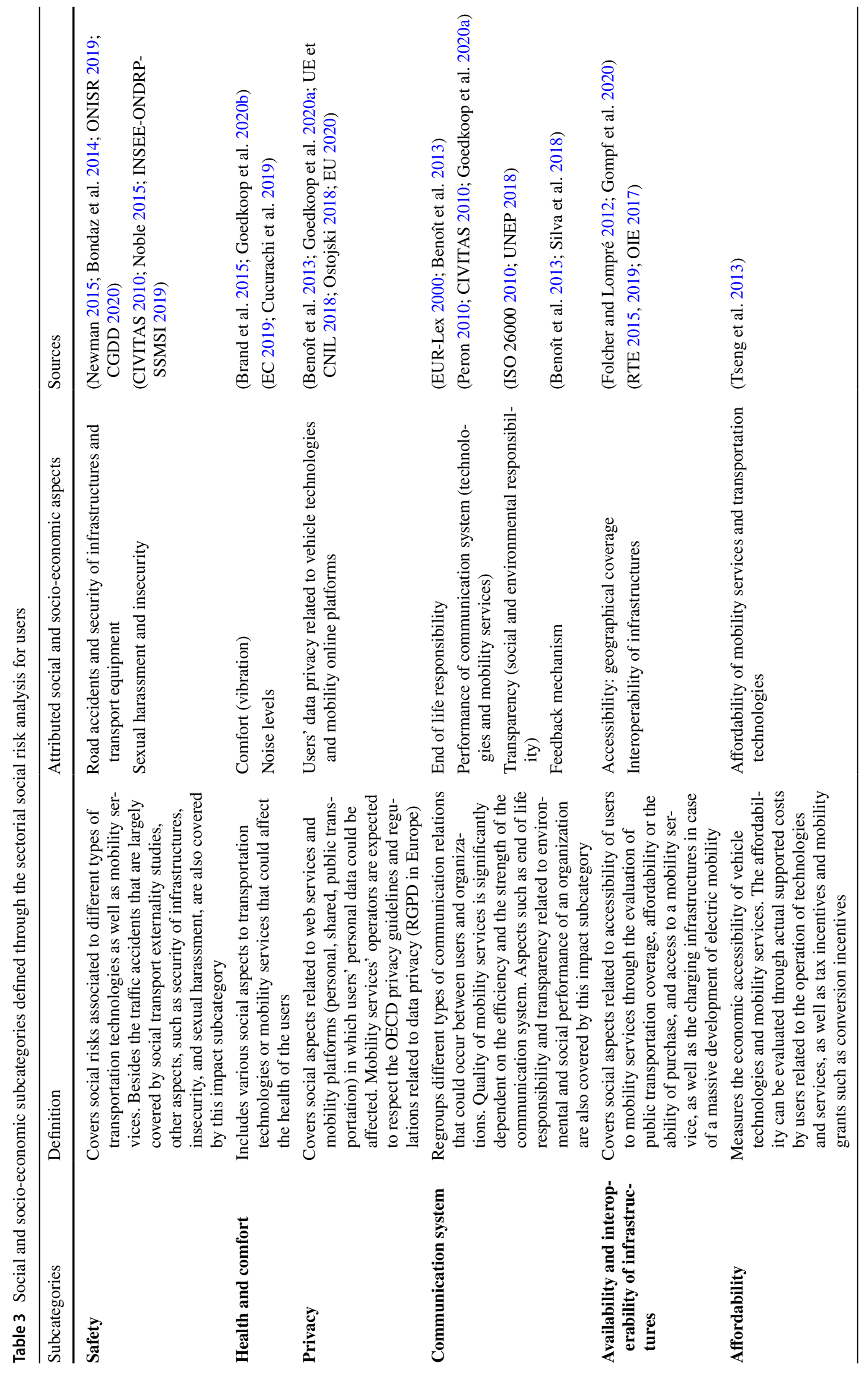



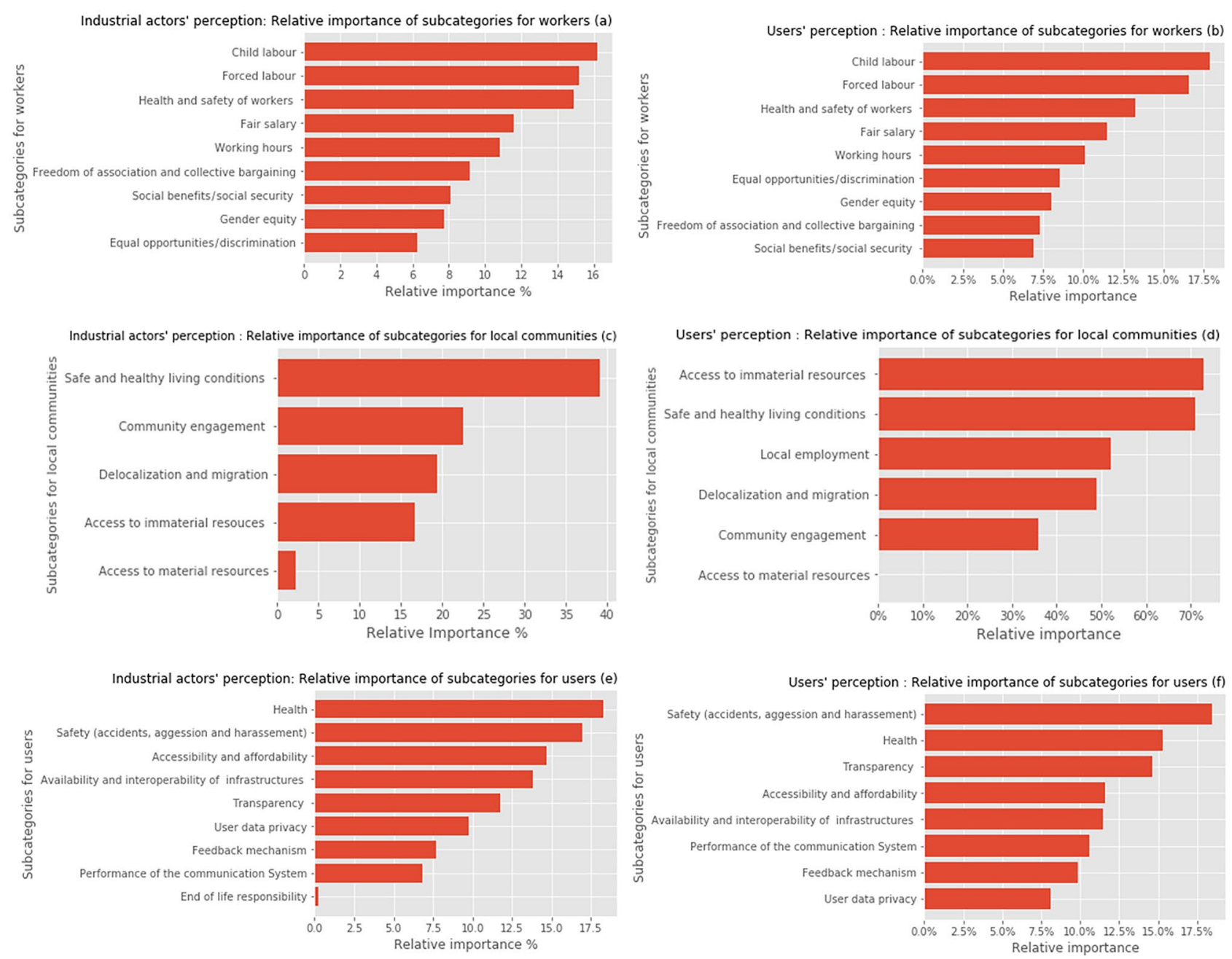

Fig. 4 Prioritization of social and socio-economic topics for workers', local communities', and users' stakeholders

interoperability of infrastructures (geographical coverage of transportation infrastructures such as collective transport station and charging infrastructures, etc.), and affordability (e.g., economic accessibility to the vehicle technology or mobility service).

We attribute several social and socio-economic aspects to measure the social performance/risk of the impact subcategories that are not included in S-LCA main references. The impact subcategory, called "availability and interoperability of the infrastructures," is therefore proposed to allow the evaluation of the inclusiveness of transportation technologies and mobility services according to the geographical coverage of mobility infrastructures (Folcher and Lompré 2012; Gompf et al. 2020). Other impact subcategories, such as "affordability and accessibility," are also defined and could play an important role in social acceptance of emergent transportation technologies (Tseng et al. 2013). In addition, other existing impact subcategories are adapted to cover more specific aspects related to mobility sector.
Thus, "communication system" regroups different types of communication relations that could occur between users and organizations. The quality of mobility services is significantly dependent on the efficiency and the strength of the communication system (CIVITAS 2010). The impact subcategory "performance of the communication system" is therefore added to allow the evaluation of the delivered information to primary users and to independent repairmen (as secondary users) through mobility platforms (Silva et al. 2018). Other impact subcategories, such as "end of life responsibility," "transparency," and "feedback mechanism," are also covered to enable the evaluation of the delivered information related to social and environmental performance of an organization. Definitions of each of the suggested impact subcategories as well as the used references are provided in Table 3.

As previously explained, the defined impact subcategories for users' stakeholder category and their related aspects could not be evaluated through a generic database due to the 
lack of correlation with the used activity variable and the lack of inventory indicators. It is therefore recommended to define social inventory indicators and adequate characterization models for users in future research studies.

\section{Stage 2: Prioritized impact subcategories following the designed consultation process Results of the prioritized} social and socio-economic impact subcategories for five stakeholder categories are discussed in this section from two different perspectives of the consulted actors. These results are based on the designed consultation process defined in Table 1, covering the three defined surveys. Figure 4(a), (b), (c), and (d) illustrate results of the conducted consultation process, accounting for both industrial actors' and users' perspectives on workers and local communities impact subcategories (case outside Europe). Figure 4(e) and (f) reveal the prioritization results for users' stakeholder group following those identified in stage 1 from both industrial actors' and users' perspectives. All the results from the prioritization stage were generated using Python-Jupyter Notebook.

Additional results about value chain actors and society stakeholder groups, together with the prioritized impact subcategories for workers and local communities in the use phase (France-specific case) and results of other consulted actors (worker union, academic actors, and public actors), are further illustrated in the supporting information, S4.

- Workers' impact subcategories: In Fig. 4(a) and (b), results of the prioritization from both industrial and user perceptions for workers subcategories outside Europe show that "child labor," "forced labor," and "health and safety of workers" are perceived by the consulted actors as the most relevant ones. These prioritized impact subcategories were assessed using the PSILCA database. The chosen indicators to perform the evaluation are listed in Table 2. For workers' impact subcategories in France, the results are disclosed in the supporting information, S4. The prioritization reveals that "working hours," "fair salary," "health and safety living conditions," and "freedom of association and collective bargaining" are classified with the highest priority by the consulted actors, including industrial actors, users, and worker unions. As an initial observation, such prioritization highlights the influence of the geographical context on the point of view of the consulted actors. Indeed, these actors showed more concern for certain aspects or others depending on the considered geographical location. Given the regulation context in France, no social risk is perceived for "child labor" or "forced labor" and the subcategories are, consequently, not relevant for the evaluation of subcategories for workers' in France compared to other impact subcategories such as "fair salary" or "worker hours." The conducted individual interviews confirm this statement as several respondents justify their answers by referring to "the pyramid of needs" allowing them to rank the different impact subcategories according to the likely presence of social risks and the level of development and performance of the associated regulations in each country.

- Local communities' impact subcategories: The relevance of impact subcategories is perceived differently depending on the consulted actors, as shown in Fig. 4(c) and (d). The industrial actors consider "safe and healthy living conditions," "community engagement," and "delocalization and migration" as the most relevant impact subcategories for the evaluation. On the other hand, as represented in Fig. 4(d), "safe and healthy living conditions," "access to immaterial resources," and "local employment" are perceived as the most relevant by users. Following these results, we selected the impact subcategories that were most prioritized by all the consulted actors to perform the S-LCIA phase. They can be listed as follows: "safe and healthy living conditions," "local employment," and "delocalization and migration." Table 2 lists the selected impact subcategories from the prioritization and the attributed indicators for their assessment. The consulted industrial actors and users emphasized the importance of the considered scope when ranking the different impact subcategories, given the variable regulatory context. Thus, the most relevant impact subcategories for local communities outside Europe are different from those located in France. Results for the case in France are presented in supporting information, S4.

- Users' impact subcategories: Fig. 4(e) and (f) show results of the prioritization of impact subcategories for users' stakeholder category according to industrial actors' and users' perceptions. The impact subcategories "health," "safety," and "accessibility and affordability" are the most relevant impact subcategories from the industrial actors' point of view, while the results from the consulted users show that "safety," "health," and "transparency" are the most important. According to industrial actors, "transparency" appears in the fifth position after "the availability and operability of infrastructures." The observed difference in ranking "transparency" confirms the uprising concern of users about the delivered information on social and environmental performance of organizations related to transportation technologies. This should be analyzed in depth in future assessments.

- Value chain actors' impact subcategories: Results, presented in the supporting information S4, show that "promotion of social responsibility" is the most relevant considering the consulted actors' perspectives, followed by "fair competition" and "respect of intellectual property rights" and finally "supplier relationships." To perform S-LCIA phase, both "promotion of social responsibility" and "fair competition" are analyzed. These have been 
selected to perform the S-LCIA phase as the PSILCA database did not cover other impact subcategories that were prioritized.

- Society's impact subcategories: Results, presented in supporting information S4, show that "corruption," "contribution to socio-economic development," "technology development," and, finally, "prevention and mitigation of armed conflicts" are perceived as the most relevant for the evaluation of electric and conventional technologies. However, the provided indicators in PSILCA database only account for two impact subcategories "contribution to economic development" and "health and safety." We have therefore analyzed "contribution to economic development" in the S-LCIA phase as it represents the priority impact subcategory for the different consulted actors while "health and safety" impact subcategory was excluded from the prioritization step.

\subsection{Comparison of the social relevance of impact subcategories for EV and ICEV technologies}

In a second step, the consulted actors were asked to compare the relevance of the different social and socio-economic impact subcategories depending on the type of the transportation technology: conventional or electric vehicles. As an outcome, relevant impact subcategories were identified when comparing electric and conventional mobility. Figure 5(a), (b), and (c) show the results for users, workers, and local communities from the different consulted actors. Some of the impact subcategories appear to be more important in case of electric mobility evaluation compared to conventional technology evaluation.

Figure 5(a) demonstrates that for users' impact subcategories, "accessibility and affordability," "availability and interoperability of infrastructures," and "end of life responsibility" are perceived particularly important in the case of electric technologies. These results are consistent with the identified social hotspots related to the current development of electro-mobility such as the management of the batteries' end of life (Bobba et al. 2018), and high initial costs of electric vehicles technologies and complex grid capacity management in case of a mass-market uptake (Tietge et al. 2016).

For workers-related impact subcategories (Fig. 5b), "delocalization and migration" and "work security" are prioritized for electric mobility and ranked as more relevant than in the case of the conventional one which can highlight the need of a consequential assessment of social and socio-economic aspects related to a massive development of electro-mobility. It is also important to note that individual interviews with worker unions have emphasized that electro-mobility requires $25 \%$ less workforce and it is therefore crucial to account for the work security-related indicators. A study from the European Climate Foundation (2018) analyzed several social and socio-economic indicators for mobility prospective scenarios in 2030 and 2050. Such assessment revealed that employment in the automotive manufacturing sector is expected to decrease in Europe, regardless of the low-carbon transition. This is explained by the fact that battery electric vehicles are less labor intensive compared to conventional vehicles, meanwhile hybrid and plug-in hybrid electric vehicles are expected to be more labor intensive (ECF 2018). On the other hand, a net increase in employment is expected for the electricity production, hydrogen-related supply chain.

Figure $5 \mathrm{c}$ shows the obtained results for the comparison of local communities' subcategory relevance between electric and conventional technologies. According to the consulted actors, there is no significant difference in terms of the importance of subcategories between EV and ICEV. However, it can be observed that the subcategories "access to material resources" and "community engagement" were slightly more ranked than the other subcategories.

Despite the potential of this approach, the consultation process was time-consuming and restricted to a limited number of relevant impact subcategories. This could be a potential limitation for its practical application and should be further developed in future studies. As no similar study has been conducted before, to the best of our knowledge, the sample size used might be questioned, yet the analysis of our results shows that the sample is homogeneous and sufficiently representative for the consulted actors and the considered transportation technologies. It is recommended, for future studies, to broaden the sample size, if possible, and confirm its consistency to enhance results representativity.

\subsection{Comprehensive analysis of S-LCIA results for mobility scenarios}

The RS-LCIA phase is conducted for the prioritized social and socio-economic impact subcategories selected from the prioritization stage. Table 2 lists the selected impact subcategories and the inventory indicators used from the PSILCA database for their evaluation.

\section{- S-LCIA results for workers}

The results for workers' impact subcategories are presented in Fig. 6. The figure illustrates impact subcategories that were perceived as the most relevant following the designed participatory approach, corresponding to "child labor," "health and safety of workers," and "forced labor." Four inventory indicators were selected to measure social risks for: child labor, total [CL medium risk $\mathrm{h}$ ], fatal accidents [FA medium risk $\mathrm{h}$ ], non-fatal accidents [NFA medium 


\section{Users subcategories : comparison of electric mobility and conventional mobilty (a)}

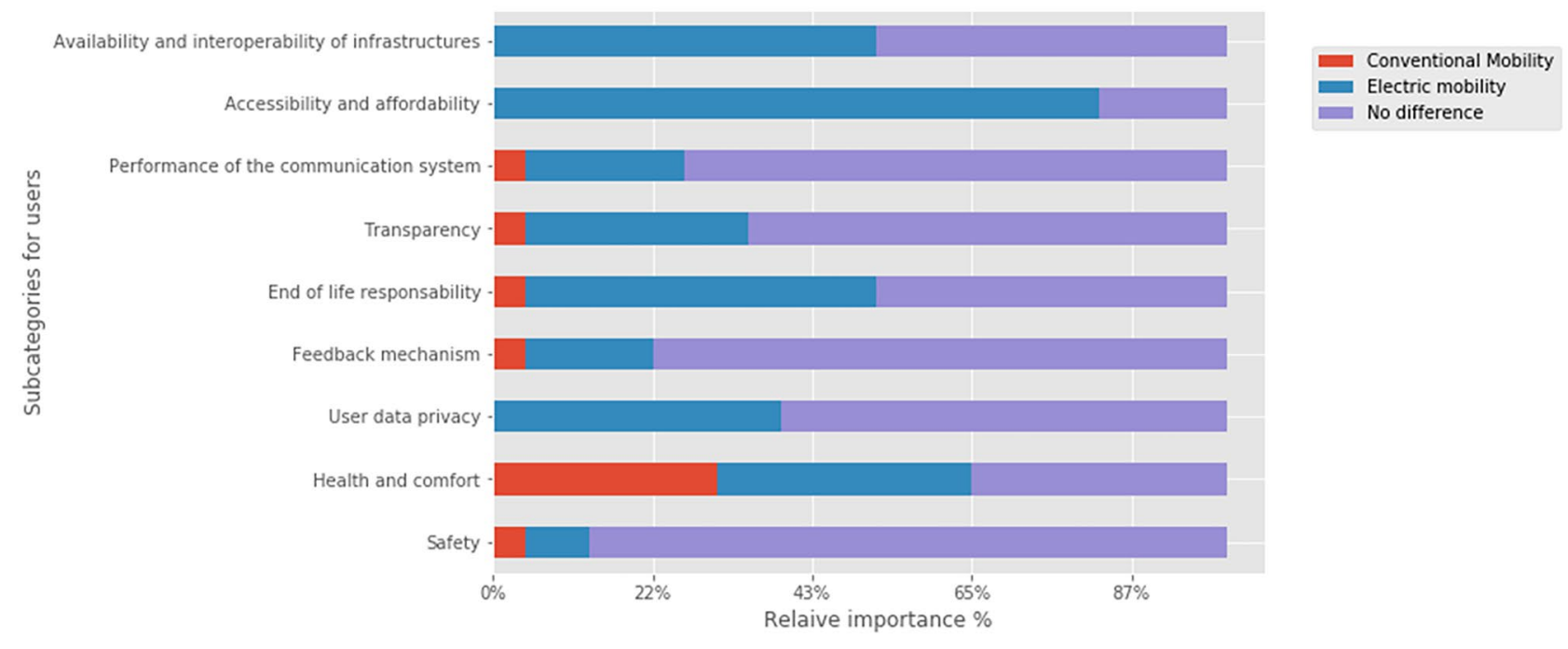

Workers subcategories : comparison of electric mobility and conventional mobilty (b)

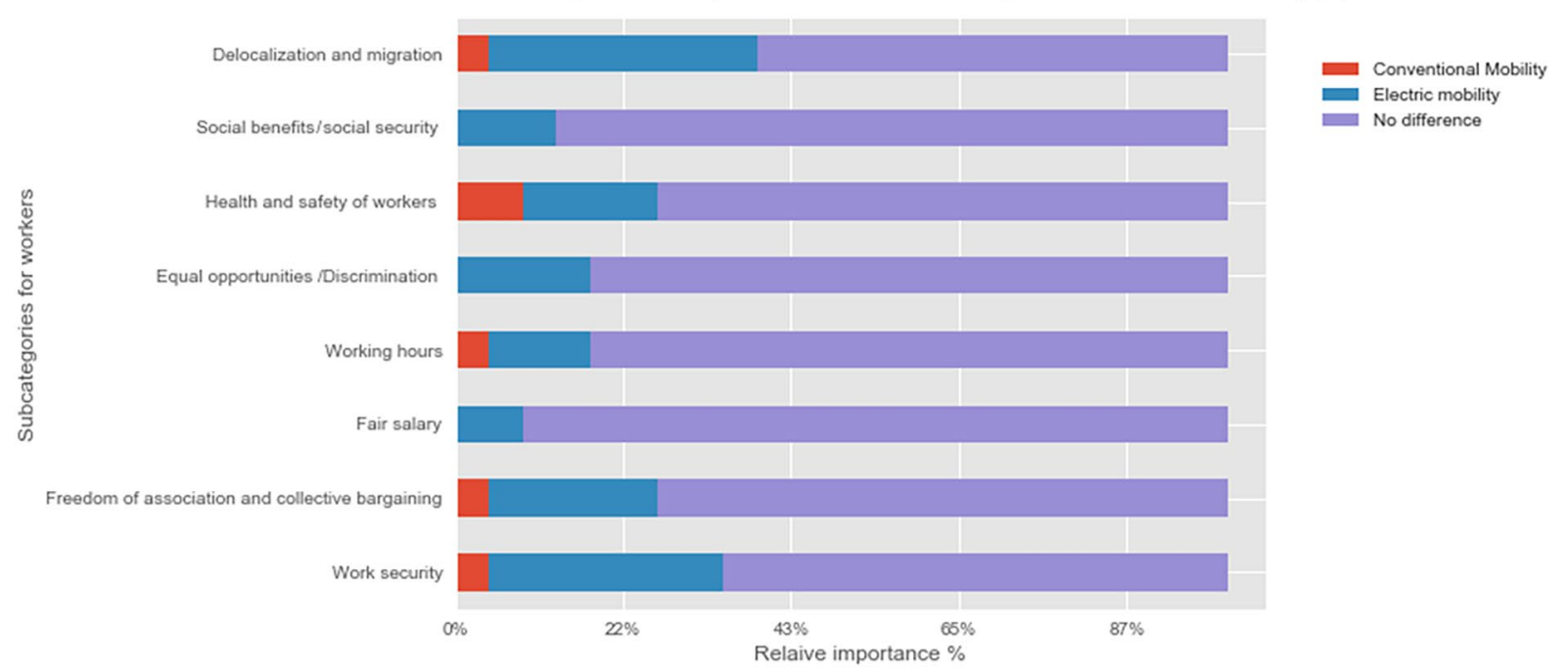

Subcategories for local communities: comparison of electric mobility and conventional mobilty (c)

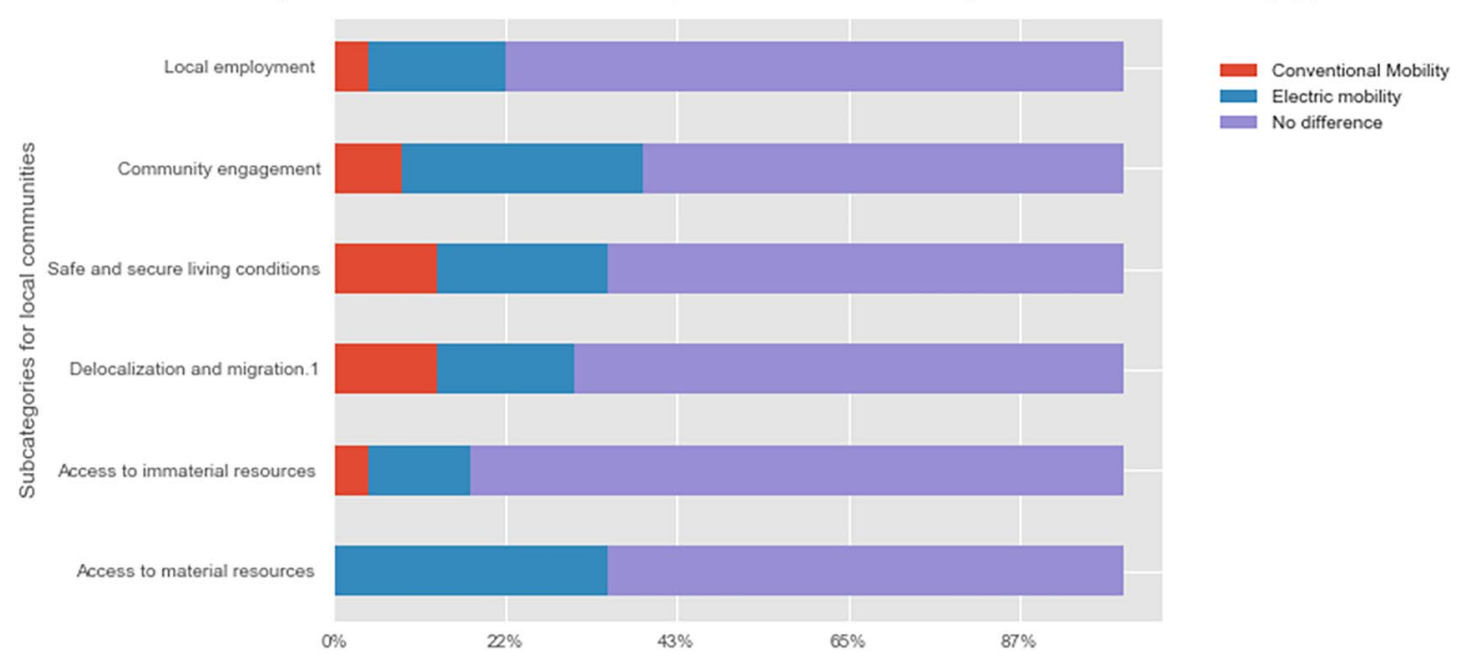

Fig. 5 Comparison of the relevance of subcategories for electric and conventional transportation technologies 

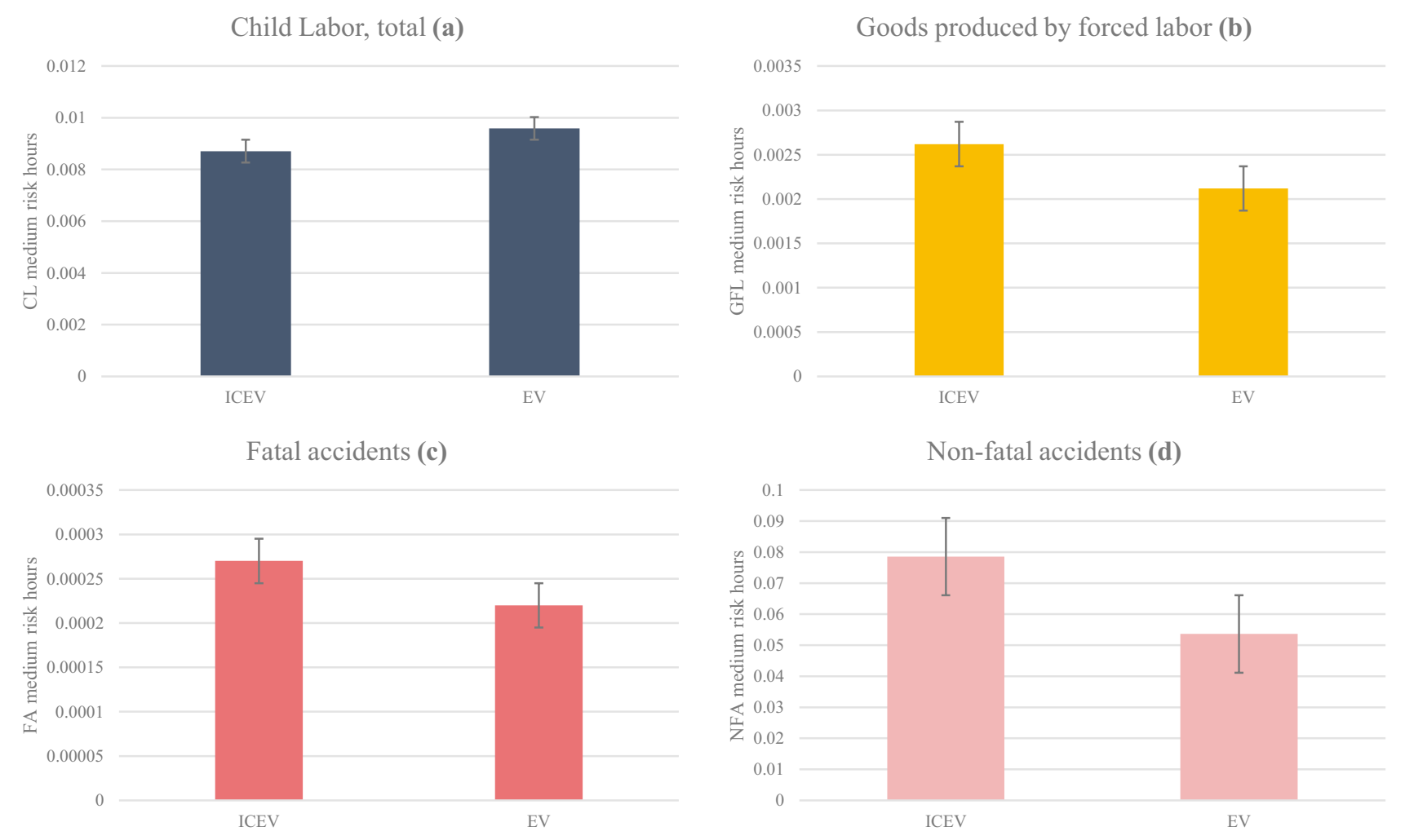

Fig. 6 Results of the evaluation of social inventory indicators through the PSILCA database for workers for both electric (EV) and conventional (ICEV) transportation technologies

risk $\mathrm{h}$ ], and goods produced by forced labor [GFL medium risk h].

Child labor: The calculated indicator for total child labor [CL medium risk $\mathrm{h}]$ is higher for $\mathrm{EV}$ technology production than the conventional transportation technologies. The contribution analysis shows that for EV technologies, the supply chain of motor vehicles manufactured in France accounts for $60.10 \%$ of the total CL medium risk h, and a share of $35 \%$ is linked to battery production supply chain in Japan while electricity production in France represents $2 \%$ of the obtained results. For ICEV production, manufacturing of the vehicles took $97.14 \%$ of the total amount of CL medium risk $\mathrm{h}$ related mainly to extraction and manufacturing process activities outside Europe. The analysis of battery production supply chain in Japan reveals that the main contributors for child labor are non-ferrous metals extraction activities in South Africa (16.34\%) and regenerated lead and zinc production in Japan (11.56\%).

The analysis of the geographical coverage of both EV and ICECV processes allows the identification of countries that have the highest scores for social risks. We have consequently observed that, for EV technologies, child labor risks arise mainly from process activities in Russia with $42.64 \%$ of total CL medium risk h due to mining and quarrying activities for energy production and non-ferrous metals manufacturing, and China with $26.90 \%$ of total CL medium risk $\mathrm{h}$ related mostly to electric machinery and equipment, plastics and metal products, and communications equipment manufacturing. For ICEV technologies, China has the highest share of contributor process activities with $44.32 \%$ of total CL medium risk $\mathrm{h}$ associated mainly to extraction of raw materials (metal products, plastic products, steel and iron, electronic elements and devices, and raw chemical materials), followed by manufacturing supply chain in France (17.45\% of total CL medium risk h), while Russia presented a share of $11.48 \%$, linked to metal products and mining and quarrying activities for energy. Process activities in Russia are mainly associated to the supply chain of battery production in Japan, which may explain the limited contribution share for ICEV compared to EV technologies and also the difference observed in Fig. 6a for this indicator between the two technologies. Recycling activities in France did not present any social risk related to child labor for both processes.

Forced labor: Fig. $6 \mathrm{~b}$ illustrates the results for goods produced by forced labor [GFL medium risk $\mathrm{h}$ ]. ICEV technologies present higher social risk ( $0.00262 \mathrm{GFL}$ medium risk $\mathrm{h})$ compared to EV technologies (0.00212 GFL medium risk h). The main process activities that are contributing to forced labor in the case of EV technologies are as follows: motor 
Drinking water coverage (a)
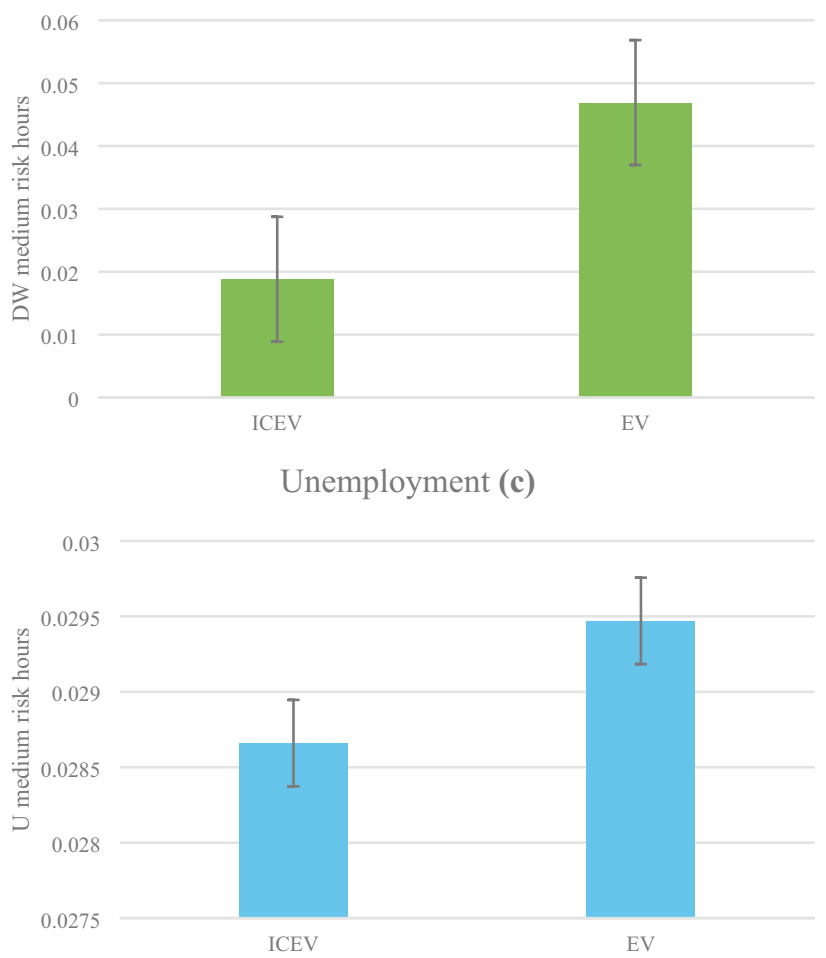

Pollution level of the country (b)
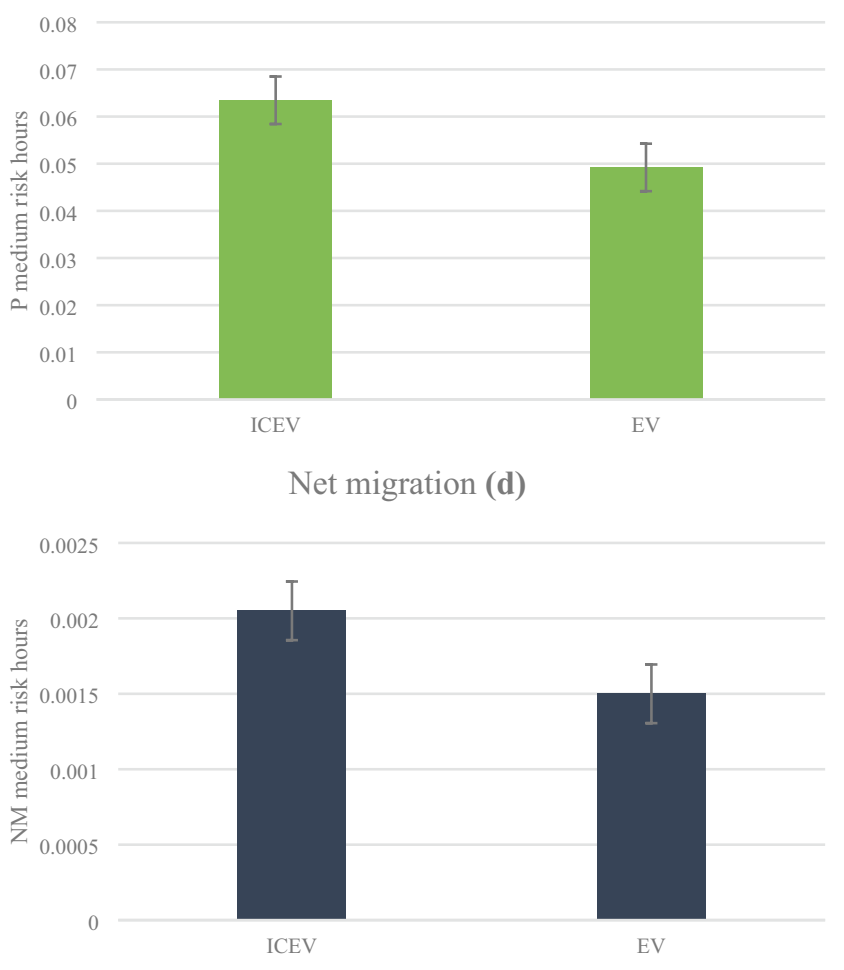

Fig. 7 Results of the evaluation of inventory indicators for local communities through the PSILCA database for both electric (EV) and conventional (ICEV) transportation

vehicle manufacturing supply chain in France (75\% share of tot GFL medium risk $\mathrm{h}$ ), followed by battery production ( $12 \%$ of total GFL medium risk $\mathrm{h}$ ) and finally the electricity production (3.68\%). In the case of ICEV technologies, the amount of goods produced by forced labor is mainly linked to the France vehicle manufacturing supply chain $(90.50 \%)$. Energy-related services (raw petroleum products' extraction, refining, and manufacturing) in France could be a significant factor for such result as the main process contributing associated to ICEV manufacturing is other business services in France.

Health and safety of workers: Two inventory indicators are calculated to analyze health and safety of workers and are illustrated in Fig. 6(c) and (d) corresponding to fatal accidents [FA medium risk $\mathrm{h}$ ] and non-fatal accidents [NFA medium risk h]. For both indicators, ICEV technologies presented a higher social risk compared to EV technologies. Concerning the latter, motor vehicle production in France presented $74.67 \%$ of total FA medium risk $h$, followed by battery production in Japan by $13.01 \%$ FA mid-risk hours. For ICEV, $90.64 \%$ of FA medium risk h is related to motor vehicle production in France. Despite the significant advances in safety regulations at work, France still presents a higher fatal accident rate than the European average with 2.74 per 100,000 persons employed in France against 1.77 in Europe (Eurostat 2020a). The countries that presented the highest social risks for fatal accidents related to EV technologies are France (vehicle manufacturing process), followed by China (metal products and raw materials extraction), Japan (battery production), and finally Spain (vehicle part manufacturing supply chain). The analysis of contributing processes to non-fatal accidents reveals that vehicle production activities, metal products manufacturing, and recycling in Spain were responsible for $40.35 \%$ of total NFA medium risk h, while it presented $11 \%$ in France mostly linked to the construction sector, and finally Turkey that presented around $4 \%$ of total FA medium risk h, where manufacturing activities for textiles, basic metal products, and motor vehicles are the main contributors. France and Spain presented the higher incidence rates per 100,000 persons employed in 2018 for non-fatal accidents in Europe (Eurostat 2020b). Mining, manufacturing, and construction sectors are the major sources of both fatal and non-fatal accidents in Europe, which also tend to be male-dominated sectors, explaining the relatively higher number of work-related accidents among men compared to women (Eurostat 2020c).

\section{- S-LCIA results for local communities}


Results of the S-LCIA evaluation phase for local communities' impact subcategories are presented in Fig. 7. It corresponds to those subcategories perceived as the most relevant for the evaluation of electric and conventional transportation technologies. The calculated indicators from the PSILCA database are as follows (Maister et al. 2020): drinking water coverage [DW mid risk h] and DALYs due to indoor and outdoor air and water pollution [DALY mid risk $\mathrm{h}$ ] for safe and healthy living conditions, unemployment rate [U medium risk $\mathrm{h}]$ for local employment, and finally net migration [NM medium risk $\mathrm{h}$ ] for migration and delocalization impact subcategories. Figure 7(a), (b), (c), and (d) show the results for the selected social and socio-economic impact subcategories of both electric and conventional transportation technologies.

Healthy and safe living conditions: Results for this indicator are showed in Fig. 7(a), (b) obtained for the two calculated indicators within this impact subcategory. EV technologies present higher social risks for the drinking water coverage [DW medium risk $\mathrm{h}$ ] and on the other hand ICEV technologies present higher social risks for DALYs due to indoor and outdoor air and water pollution. To investigate these results, we took a closer look into the contributor processes for each indicator. Battery production was found responsible for $65.18 \%$ of total DW medium-risk hours in the case of EV technologies due to mineral extraction activities (namely, non-ferrous metals in Russia, lead and zinc in Japan, and basic metals extraction in Mexico). Motor vehicle manufacturing in France presents $28.51 \%$ of total DW medium-risk hours, followed by electricity supply chain in France with 3\% associated with mining activities for energy and nuclear fuel production. In the case of ICEV technologies, social risks are mostly related to motor vehicle manufacturing with $98.68 \%$ of total DW mediumrisk hours associated to mineral extraction and refined petroleum products. These results can be explained by the significant dependency of mining activities to water consumption which could decrease the accessibility of local communities to water resources and affect their quality (Northey et al. 2019). The second indicator that was analyzed within this impact subcategory is the pollution level of the country [P medium risk $\mathrm{h}$ ] based on the pollution index by Numbeo (2019) due to water pollution, air pollution, noise levels, green parks in the city, etc. The contribution analysis demonstrates that for EV technologies, motor vehicle supply chain in France is responsible for $83.10 \%$ of tot $\mathrm{P}$ medium risk $\mathrm{h}$ associated with various extraction and production activities that take place in China, while $11.41 \%$ of tot $\mathrm{P}$ medium risk $\mathrm{h}$ is generated by battery production due mostly to non-ferrous metals activities in Russia. For ICEV technologies, France's supply chain for motor vehicles is responsible for $96.08 \%$ of pollution-related social risks [P medium risk $\mathrm{h}$ ] that are linked to the significant number of extraction and manufacturing processes in China. In fact, the geographical analysis of the various processes showed that for the two analyzed transportation technologies, the major source of social risks is induced by activities located in China (52.469\% of total P medium-risk hours for EV technologies and $61.39 \%$ of total P medium-risk hours for ICEV technologies).

Local employment: Fig. 7(c) shows the obtained results for unemployment indicator [U medium risk h]. Electric transportation technologies show more significant social risks in terms of the unemployment rate due to battery production that gives place to more extraction and manufacturing processes for non-ferrous metals and other mining activities in South Africa. The major contributor process activity for both electric and conventional technologies is related to motor vehicle production in France $(50.39 \%$ of total U medium risk $\mathrm{h}$ ) and Spain (31.47\% of total U medium risk h) in the case of EV technologies, which can be explained by the delocalization of mineral extraction processes and battery manufacturing in China and South Africa.

Migration and delocalization: Results of the net migration indicators [NM medium risk $\mathrm{h}$ ] calculated for both EV and ICEV technologies, illustrated in Fig. 7(d), confirm the last assumption made for unemployment rate results. In fact, following the contribution analysis, motor vehicle production in Spain appears to be the major source of social risks related to this impact subcategory accounting for $45.40 \%$ of total NM medium risk $\mathrm{h}$ in the case of EV technologies and $46.83 \%$ of total NM medium risk $h$ in the case of ICEV technologies.

\section{- S-LCIA results for value chain actors}

The analysis of S-LCIA results for impact subcategories related to value chain actors is conducted for the "promotion of social responsibility" and "fair competition" that were selected based on the participatory approach.

Promotion of social responsibility: The proposed indicator by PSILCA database to evaluate the promotion of social responsibility examines the number of companies involved in corporate social responsibility policy along the supply chain (Maister et al. 2020). For both EV and ICEV technologies, the main contributing processes to the promotion of social responsibility (positive effects) are associated to manufacturing activities located in Europe (France and Spain) which in part can be explained by the European regulatory context and the rise of ecological awareness related to environmental and social performances of organizations. Results for this impact subcategory are illustrated in the supporting information, S5.

Fair competition: The measured indicator for fair competition, anti-competitive behavior of organizations, demonstrates similar results for both EV and ICEV technologies 
(0.00848 AC medium risk h). Results for this impact subcategory are illustrated in the supporting information, S5. The contribution analysis allowed identifying the main contributing process activities for these results. For electric vehicles, motor vehicle manufacturing in France is responsible for $76.54 \%$ of total AC medium risk h associated mainly with refined petroleum products, followed by electricity production and hot water supply in France that present $17.72 \%$ of total $\mathrm{AC}$ medium risk $\mathrm{h}$ and finally battery production in Japan with $3 \%$ of total AC medium risk $\mathrm{h}$. The high identified social risks for $\mathrm{AC}$ medium risk that is associated to the use of refined petroleum products come only from motor vehicle production (without battery production). On the other hand, motor vehicle production for ICEV technologies is the main contributor to social risks related to anticompetitive behavior (97.06\%), mostly related to mining and quarrying activities for energy in Russia (17.38\%) and Algeria (2.61\%), and other services incidental to oil and gas extraction in France. All the identified process activities for both EV and ICEV related to fair competition impact subcategory highlight the high likelihood of anti-competitive behavior associated to the energy sector. Achieving social sustainability in future mobility scenarios should focus on improving the social performance of the energy sector on which electric mobility strongly relies.

\section{- S-LCIA results for society}

Contribution of the sector to economic development: The measured indicator for society's impact subcategory is the contribution of the sector to economic development [CED medium-risk $h$ ]. This indicator accounts for positive impacts by measuring opportunity levels presented by the evaluated process activity. For both EV and ICEV technologies, motor vehicle manufacturing presented the higher share of CED medium risk $\mathrm{h}$, mostly related to research and development activities. Results for this impact subcategory are illustrated in the supporting information, S4.

As a general outcome, the S-LCIA evaluation phase is very challenging as very few studies consider a complete product system in S-LCA (Ciroth and Franze 2011); they rather focus on one specific process activity (Pastor et al. 2018; Werker et al. 2019). Modeling transportation technologies requires considering multiple input processes for which data is often scarce. We extrapolated available data for similar processes in the PSILCA database to model the two considered scenarios. It is therefore important to note that further work should account for large uncertainties when analyzing the results. Future enhancement of database transparency is also recommended to better identify individual contributions in the S-LCIA phase.

\section{Conclusions and recommendations}

Throughout this research, a comprehensive methodological framework for S-LCA was described step-by-step. This S-LCA framework was adapted all along the four S-LCA phases recommended by ISO 14040 to include an innovative approach for the identification and prioritization of impact subcategories. Our study aims at providing S-LCA practitioners with a participatory approach for the selection of relevant social and socio-economic subcategories as suggested by the updated version of S-LCA guidelines (UNEP 2020). Such an approach can help duly justify the need of the used indicators in the S-LCIA phase and increase the local relevance of S-LCA results. Embedding the perception of all concerned stakeholders, as introduced in this work, for the selection of relevant impact subcategories certainly improves the representativeness and inclusiveness of the findings, compared to a materiality assessment that solely reflects the perception of designers and companies.

The identification stage enables the definition of sectorial-based impact subcategories for each stakeholder group and for the various life cycle stages. A general consultation process was designed to prioritize the identified impact subcategories and to consider the most relevant ones from the perspective of all concerned stakeholders. The selected social and socio-economic impact subcategories were then used to perform the S-LCIA phase and thus contribute to a comprehensive analysis in the interpretation phase.

The developed step-by-step S-LCA framework was implemented for a mobility scenario designed to compare electric and conventional transportation technologies for passenger use. The proposed list of social and socio-economic impact subcategories resulting from its implementation is a contribution towards harmonized social and socio-economic indicators to the mobility sector. Moreover, the implementation of the participatory approach demonstrated the interest of stakeholders' involvement within the S-LCA framework. Indeed, social significance of social and socio-economic impact subcategories has varied significantly according to each of the consulted stakeholders (e.g., users, industrial actors, public actors, worker unions). These discrepancies have revealed different concerns and interests for the considered social topics and confirm their importance to account for within the evaluation phase avoiding thus a partial representation of significant impacts. The comprehensive analysis comparing electric and conventional technologies has been performed based on the S-LCIA phase and results from the participatory approach. This phase underlined further the interest of introducing important information on stakeholders' perceptions into the interpretation of results. 
The main limitations of the proposed participatory approach are laid in its duration and sample size. In fact, the surveys and data collection were time-consuming and should be carefully designed. The sample size being dimensioned to 70 different consulted stakeholders might raise questions as no similar study has been conducted before. It is therefore recommended to broaden the sample size as much as possible. Specificities may be revealed when consulting the different stakeholders and the design of the surveys might require to be tailored to each consulted stakeholder and product system. In addition, the S-LCIA phase in our case study was carried out through a generic impact assessment using the PSILCA database which did not include user-dependent impact subcategories.

Considering mobility scenarios, further research should focus on evaluating user's choices to enable a global social evaluation including both technologies and services (personal, public, and shared transport). Furthermore, users' stakeholder group should not be left out in S-LCA studies. The designed approach allowed the identification of userdependent social and socio-economic impact subcategories and their perception in the prioritization stage. Yet, their evaluation in the S-LCIA phase was not possible due to the lack of data and missing correlation with the used activity variable. These could be further evaluated through specific impact assessments. The application to different case studies with new activity variables besides worker hours may allow covering potential social and socio-economic impact subcategories valid for all stakeholder groups.

Although the present work did not cover the new proposed stakeholder categories and impact subcategories by UNEP guidelines, the proposed step-by-step S-LCA framework is fortunately general enough to integrate these categories. Future research can focus not only on adding new impact subcategories and stakeholder categories but also on the application of the framework to other product systems and sectors.

The comprehensive methodological framework, developed in our work, paves the way for more operational S-LCA studies that promote all stakeholders' involvement. The stepby-step description may serve to guide S-LCA practitioners for applications to other case studies and sectors. The development of such framework is essential to strengthen an integrated sustainability assessment to support the decision-making process based on social, environmental, and economic pillars.

Supplementary Information The online version contains supplementary material available at https://doi.org/10.1007/s11367-021-01988-w.

Acknowledgements The authors want to thank Prof. Madeleine Akrich, from MINES ParisTech - PSL University, for her advice and propositions to enhance the survey and data collection, ADEME, French worker unions, EcoSD Network for the survey sharing, and all the respondents that took time to answer and give feedback on the addressed questions.

Open Access This article is licensed under a Creative Commons Attribution 4.0 International License, which permits use, sharing, adaptation, distribution and reproduction in any medium or format, as long as you give appropriate credit to the original author(s) and the source, provide a link to the Creative Commons licence, and indicate if changes were made. The images or other third party material in this article are included in the article's Creative Commons licence, unless indicated otherwise in a credit line to the material. If material is not included in the article's Creative Commons licence and your intended use is not permitted by statutory regulation or exceeds the permitted use, you will need to obtain permission directly from the copyright holder. To view a copy of this licence, visit http://creativecommons.org/licenses/by/4.0/.

\section{References}

Aparcana S, Salhofer S (2013) Application of a methodology for the social life cycle assessment of recycling systems in low income countries: three Peruvian case studies. Int J Life Cycle Assess 18(5):1116-1128. https://doi.org/10.1007/s11367-013-0559-3

Arvidsson R (2019) On the use of ordinal scoring scales in social life cycle assessment. Int J Life Cycle Assess 24(3):604-606. https:// doi.org/10.1007/s11367-018-1557-2

Azapagic A (2004) Developing a framework for sustainable development indicators for the mining and minerals industry. J Clean Prod 12(6):639-662. https://doi.org/10.1016/S0959-6526(03) 00075-1

Aznar-Sánchez JA, Velasco-Muñoz JF, Belmonte-Ureña LJ, ManzanoAgugliaro F (2019) Innovation and technology for sustainable mining activity: a worldwide research assessment. J Clean Prod 221:38-54. https://doi.org/10.1016/j.jclepro.2019.02.243

Benoît N, Catherine JF, Valdivia S, Traverso M, Vickery G, et Siddharth P (2013) The methodological sheets for subcategories in social life cycle assessment (SLCA). https://www.lifecycleinitiative.org/ wp-content/uploads/2013/11/S-LCA_methodological_sheets_11. 11.13.pdf

Benoit-Norris C, Cavan DA, Norris G (2012) Identifying social impacts in product supply chains:overview and application of the Social Hotspot Database. Sustainability 4(9):1946-1965. https://doi. org/10.3390/su4091946

Bjørgen A, Fossheim K, et Macharis C (2021) How to build stakeholder participation in collaborative urban freight planning. Cities 112 (mai): 103149. https://doi.org/10.1016/j.cities.2021. 103149

Bobba S, Podias A, Di Persio F, Messagie M, Cusenza MA, Eynardu U, Fabrice M, et Pfrang A (2018) Sustainability assessment of second life application of automotive batteries (SASLAB). JRC Technical Reports. https://publications.jrc.ec.europa.eu/ repository/bitstream/JRC112543/saslab_final_report_2018_ 2018-08-28.pdf

Bondaz M, Panhaleux J, Helbronner C, Paquette O, Miramon G, Sion L, Aubert D, et Bodino P (2014) Evaluation de la politique de sécurité routière : Rapport de diagnostic (Tome1). https://www. vie-publique.fr/sites/default/files/rapport/pdf/154000563.pdf

Brand MJ, Schuster SF, Bach T, Fleder E, Stelz M, Gläser S, Müller J, Sextl G, et Jossen A (2015) Effects of vibrations and shocks on lithium-ion cells . J Power Sources 288 (août): 62-69. https://doi. org/10.1016/j.jpowsour.2015.04.107

Cerdas F, Egede P, et Herrmann C (2018) LCA of electromobility. In Life cycle assessment, édité par Michael Z. Hauschild, Ralph K. Rosenbaum, et Stig Irving Olsen, 669-93. Cham: Springer 
International Publishing. https://doi.org/10.1007/978-3-31956475-3_27.

CGDD, Datalab (2020) Bilan social annuel du transport routier de voyageurs - Édition 2020. http://temis.documentation.devel oppement-durable.gouv.fr/docs/Temis/0080/Temis-0080643/ 21584_2020.pdf

Chalkia E, Mueller B et L'Hostis A (2017) The role of societal resistance in transportation innovation. In 8th International Congress on Transportation Research: Transportation by 2030: Trends and Perspectives, 12P. France. https://doi.org/10.5281/zenodo. 1216917

Ciroth A, Di Noi C, et Srocka M (2019) Revisiting the activity variable in social LCA beyond worker hours. Présenté à LCA XIX, Tucson. https://www.greendelta.com/wp-content/uploads/2019/11/ 2019_LCA_XIX_Revisiting-the-activity-variable-in-SLCA.pdf

Ciroth A, et Franze J (2011) LCA of an ecolabeled notebook : consideration of social and environmental impacts along the entire life cycle. GreenDelta. https://www.greendelta.com/wp-content/ uploads/2017/03/LCA_laptop_final.pdf

CIVITAS (2010) Amélioration de la qualité des services de transport en commun. Policy advice notes. http://civitas.eu/sites/default/files/ civitas_ii_policy_advice_notes_11_public_transport_quality_fr.pdf

CNIL (2016) Pack de conformité : Véhicules connectés et données personnelles. https://www.cnil.fr/sites/default/files/atoms/files/ pack_vehicules_connectes_web.pdf

CNIL (2018) Délibération de la formation restreinte ${ }^{\circ}$ SAN-2018011 du 19 décembre 2018 prononçant une sanction pécuniaire à l'encontre de la société X. https://www.legifrance.gouv.fr/cnil/

Coderre-Proulx M, Campbell B, et Mandé I (2016) International migrant workers in the mining sector. Report. Geneva: International Labour Office. Sectoral Policies Dept.; International Labour Office. Conditions of Work and Equality Dept. http:// www.ilo.org/global/topics/labour-migration/publications/ WCMS_538488/lang--en/index.htm

Cox BL (2018) Mobility and the energy transition : a life cycle assessment of Swiss passenger transport technologies including developments until 2050 . Zurich: ETH Zurich. https://www.psi.ch/ta/ PublicationTab/Thesis_Embargo_free_version.pdf

Cucurachi S, Schiess S, Froemelt A, Hellweg S (2019) Noise footprint from personal land-based mobility. J Ind Ecol 23(5):1028-1038. https://doi.org/10.1111/jiec.12837

Duce D, Andrea MG, Althaus H-J (2016) Electric passenger car transport and passenger car life cycle inventories in Ecoinvent Version 3. Int J Life Cycle Assess 21(9):1314-1326. https://doi.org/10. 1007/s11367-014-0792-4

Dell RM, Moseley PT, et Rand DAJ (2014a) Chapter 8 - Hydrogen, fuel cells and fuel cell vehicles. In Towards sustainable road transport, édité par Ronald M. Dell, Patrick T. Moseley, et David A. J. Rand, 260-95. Boston: Academic Press. https://doi.org/10. 1016/B978-0-12-404616-0.00008-6.

Dell RM, Moseley PT, et Rand DAJ (2014b) Unconventional fuels. In Towards Sustainable road transport, 86-108. Elsevier. https://doi. org/10.1016/B978-0-12-404616-0.00003-7

Dreyer LC, Hauschild MZ, Schierbeck J (2010) Characterisation of social impacts in LCA. Int J Life Cycle Assess 15(3):247-259. https://doi.org/10.1007/s11367-009-0148-7

EC (2016) A European Strategy for Low-Emission Mobility. Communication from the Commission to the European Parliement, the Council, the European Economic and Social Committee and the Committee of the Regions : Europe on the move - $\operatorname{COM}(2016) 501$ final. European Commission. https://ec.europa.eu/transparency/regdoc/ rep/1/2016/EN/1-2016-501-EN-F1-1.PDF

EC (2018a) A Clean Planet for all A European strategic long-term vision for a prosperous, modern, competitive and climate neutral economy . Communication From the Commission to the European Parliament, the European Council, the Council, the
European Economic and Social Committee, the Committee of the Regions and the European Investment Bank 773. brussels: European Commission. https://eur-lex.europa.eu/legal-content/ $\mathrm{EN} / \mathrm{TXT} / \mathrm{PDF} /$ ?uri=CELEX:52018DC0773\&from $=\mathrm{EN}$

EC (2018b) EUR-Lex -On the road to automated mobility: an EU strategy for mobility of the future. https://eur-lex.europa.eu/ legal-content/EN/TXT/?uri=CELEX:52018DC0283

EC (2019) Electric and hybrid cars: new rules on noise emitting to protect vulnerable road users. https://ec.europa.eu/growth/content/electricand-hybrid-cars-new-rules-noise-emitting-protect-vulnerable-roadusers_en

ECF (2018) Low-carbon cars in Europe: asocial and socio-economic assessment . Final report. European Climate Foundation \& Cambridge econometrics. https://europeanclimate.org/wpcontent/uploads/2019/12/20-02-2019-low-carbon-cars-ineurope-a-socioeconomic-assessment-technical-report.pdf

Esztergár-Kiss D, et Tettamanti T (2019) Stakeholder engagement in mobility planning. In Autonomous vehicles and future mobility, 113-23. Elsevier. https://doi.org/10.1016/B978-0-12-817696-2. 00009-3

EU (2020) Protection des données et respect de la vie privée en ligne. L'Europe est à vous - Citoyens. 2020. https://europa.eu/youre urope/citizens/consumers/internet-telecoms/data-protectiononline-privacy/index_fr.htm

EUR-Lex (2000) Véhicules hors d'usage : Directive 2000/53/CE. https:// eur-lex.europa.eu/legal-content/FR/TXT/?uri=LEGISSUM: 121225

European Commission (2020) Technical Support Related to Sustainable Urban Mobility Indicators (SUMI). Harmonisation Guideline Final (web) version MOVE/B4/2017-358. https://ec.europa.eu/transport/ sites/default/files/sumi_wp1_harmonisation_guidelines.pdf

Eurostat (2020a) Fatal accidents at work, 2017 and 2018 (incidence rates per 100000 persons employed) AAW2020.png - Statistics Explained. 2020. https://ec.europa.eu/eurostat/statistics-explained/ index.php?title=File:Fatal_accidents_at_work,_2017_and_2018_ (incidence_rates_per_100_000_persons_employed)_AAW2020. png

Eurostat (2020b) Non-Fatal accidents at work, 2017 and 2018 (incidence rates per 100000 persons employed) AAW2020.Png. 2020. https://ec.europa.eu/eurostat/statistics-explained/index. php?title=File:Non-fatal_accidents_at_work,_2017_and_2018_ (incidence_rates_per_100_000_persons_employed)_AAW2020. png

Eurostat (2020c) Non-fatal accidents at work by size of enterprise and economic activity, EU-27, 2018 (\% of non-fatal accidents for each activity) AAW2020.Png. 16 novembre 2020. https:// ec.europa.eu/eurostat/statistics-explained/index.php?title= File:Non-fatal_accidents_at_work_by_size_of_enterprise_ and_economic_activity,_EU-27,_2018_(\%25_of_non-fatal_ accidents_for_each_activity)_AAW2020.png

Field FR, Wallington TJ, Everson M, Kirchain RE (2017) Strategic materials in the automobile: a comprehensive assessment of strategic and minor metals use in passenger cars and light trucks. Environ Sci Technol 51(24):14436-14444. https://doi.org/10. 1021/acs.est.6b06063

Finkbeiner M, Inaba A, Tan R, Christiansen K, Klüppel H-J (2006) The New International Standards for Life Cycle Assessment: ISO 14040 and ISO 14044. Int J Life Cycle Assess 11(2):80-85. https://doi.org/10.1065/lca2006.02.002

Folcher, V, et Lompré N (2012) Accessibilité pour et dans l'usage : concevoir des situations d'activité adaptées à tous et à chacun. Le travail humain Vol. 75 (1): 89-120. https://www.cairn.info/ revue-le-travail-humain-2012-1-page-89.html

Fontes J, Gaasbeek A, Goedkoop M, Contreras S, et Evitts S (2016) Handbook for product social impact assessment 3.0. PréSustainability. https://doi.org/10.13140/RG.2.2.23821.74720 
Garrido FA (2018) Towards transport futures using mobile data analytics: stakeholder identification in the city of Stockholm. KTH, School of Architecture and the Built Environment (ABE), https:// www.diva-portal.org/smash/get/diva2:1273115/FULLTEXT01. pdf

Goedkoop M, De Beer I, Harmens R, Saling P, Morris D, Florea A, Hettinger AL et al (2020a) Product social impact assessment handbook 2020. https://product-social-impact-assessment.com/ wp-content/uploads/2020/12/20-01-Handbook-2020_10.pdf

Goedkoop M, De Beer I, Harmens R, Saling P, Morris D, Florea A, Hettinger AL et al (2020b) Product Social Impact Assessment- Social Topics Report - 2020. Amersfoort. https://produ ct-social-impact-assessment.com/wp-content/uploads/2020/11/ Social-Topics-Report-2020_06.pdf

Gompf K, Traverso M, Hetterich J (2020) Towards social life cycle assessment of mobility services: systematic literature review and the way forward. Int J Life Cycle Assess 25(10):18831909. https://doi.org/10.1007/s11367-020-01788-8

Graham I (2010) Working conditions of contract workers in the oil and gas industries . Working paper Working paper 276. International Labour Office. http://www.ilo.org/sector/Resources/ publications/WCMS_161194/lang--en/index.html

GRI (2011) G3-Sustainaability Reporting Guidelines . 3.1. Amsterdam: Global Reporting Initiative. https://www.globalreporting.org/

GRI (2016) GRI-2016-Consolidated Set of GRI Sustainability Reporting Standards. Amsterdam: Global Reporting Initiative. https:// www.globalreporting.org/

Harison P (2018) Fueling Europe's future-how the transition from oil strengthens the economy.pdf . Cambridge Econometrics. https:// www.camecon.com/how/our-work/fuelling-europes-future/

Harper G, Sommerville R, Kendrick E, Driscoll L, Slater P, Stolkin $\mathrm{R}$, Walton A et al (2019) Recycling lithium-ion batteries from electric vehicles. Nature 575(7781):75-86. https://doi.org/10. 1038/s41586-019-1682-5

Harrington TS, Srai JS, Kumar M, Wohlrab J (2016) Identifying design criteria for urban system 'last-mile'solutions-a multi-stakeholder perspective. Prod Plan Control 27(6):456-476

Hilson G, et Maconachie R (2020) Artisanal and small-scale mining and the sustainable development goals: opportunities and new directions for Sub-Saharan Africa . Geoforum 111 (mai): 125-41. https://doi.org/10.1016/j.geoforum.2019.09.006

Haque N, Mazhar I, et Biswas W (2020) Application of life cycle assessment for sustainability evaluation of transportation fuels . In Encyclopedia of Renewable and Sustainable Materials, édité par Saleem Hashmi et Imtiaz Ahmed Choudhury, 359-69. Oxford: Elsevier. https://doi.org/10.1016/B978-0-12-803581-8.10792-1

Hosseinijou SA, Mansour S, Shirazi MA (2014) Social life cycle assessment for material selection: a case study of building materials. Int J Life Cycle Assess 19(3):620-645. https://doi.org/10. 1007/s11367-013-0658-1

Hu Y, Cheng H, Tao S (2017) Retired electric vehicle (EV) batteries: integrated waste management and research needs. Environ Sci Technol 51(19):10927-10929. https://doi.org/10.1021/acs.est. $7 \mathrm{~b} 04207$

IEA (2020) Global EV Outlook 2020 : entering the decade of electric drive ? Technology report. International Energy Agency. https:// www.iea.org/reports/global-ev-outlook-2020

IIRC (2014) Cadre de référence International portant sur le reporting intégré . Internation Integrated Reporting Council. https://integratedreporting. org/

ILO (2002) The evolution of employment, working time and training in the mining industry. Report TMMI/2002. http://www.ilo.org/ global/publications/ilo-bookstore/order-online/books/WCMS_ PUBL_9221132234_EN/lang--en/index.html

INSEE-ONDRP-SSMSI (2019) Victimation 2018 et perceptions de la sécurité : Résultats de l'enquête Cadre de vie et Sécurité 2019
Institut National des Hautes Etudes de la Sécurité et de la Justice : Observatoire National de la Délinquance et des Réponses Pénales. https://www.ihemi.fr/sites/default/files/publications/ files/2019-12/RA_ONDRP_2019.pdf

International Labour Office (2001) Safety and health in the non-ferrous metals industries . Code of practice. Geneva: International Labour Office. http://www.ilo.org/global/topics/safety-and-health-atwork/normative-instruments/code-of-practice/WCMS_107713/ lang--en/index.html

International Labour Office (2005) Safety and Health in the Iron and Steel Industry - Sectoral Activities Programme . Code of practice MEISI/2005/8. Geneva. http://www.ilo.org/global/topics/ safety-and-health-at-work/normative-instruments/code-of-pract ice/WCMS_112443/lang--en/index.html

International Labour Office (2010) Benefits of improved road access . Report. Geneva: International Labour Organization (ILO). http:// www.ilo.org/jakarta/whatwedo/publications/WCMS_150112/ lang--en/index.html

International Labour Office (2015a) Impact assessment study of improved rural road maintenance system under PMGSY. Geneva: Ministry of Rural Development. https://www.ilo.org/wcmsp5/ groups/public/---ed_emp/---emp_policy/---invest/documents/ publication/wcms_434255.pdf

International Labour Office (2015b) Priority Safety and Health Issues in the Road Transport Sector - Report for Discussion at the Tripartite Sectoral Meeting on Safety and Health in the Road Transport Sector . Meeting report TSMRTS/2015. Geneva. https:// www.ilo.org/wcmsp5/groups/public/---ed_dialogue/---sector/ documents/publication/wcms_400598.pdf

International Labour Office (2015c) Occupational safety and health in the oil and gas production and oil refining sector . Resource list. http://www.ilo.org/global/topics/safety-and-health-at-work/ industries-sectors/WCMS_219028/lang--en/index.html

International Labour Office (2016) Sectoral studies on decent work in global supply chains: comparative analysis of opportunities and challenges for social and economic upgrading . Publication. Geneva: International Labour Organization (ILO). http://www.ilo.org/sector/ Resources/publications/WCMS_485367/lang--en/index.html

International Labour Office (2018) Back to the future: challenges and opportunities for the future of work addressed in ILO Sectoral Meetings since 2010. Working paper. http://www.ilo.org/sector/ Resources/publications/WCMS_628793/lang--en/index.html

International Labour Office (2019a) Occupational safety and health in the mining industry in Ukraine . Publication. International Labour Organization (ILO). http://www.ilo.org/budapest/whatwe-do/publications/WCMS_670764/lang--en/index.html

International Labour Office (2019b) International Labour Office.Scale Gold Mining (CARING GOLD MINING PROJECT): fact sheet. Fact sheet. International Labour Organization (ILO). http://www. ilo.org/manila/publications/WCMS_720740/lang--en/index.html

International Labour Office (2020) Guidelines on the promotion of decent work and road safety in the transport sector. Geneva: International Labour Organization (ILO). https://www.ilo.org/ wcmsp5/groups/public/---ed_dialogue/---sector/documents/ normativeinstrument/wcms_742633.pdf

International Labour Office (2021) Challenges and opportunities for productive employment and decent work in the natural stone mining industry supply chain in Rajasthan. Report. Geneva: ILO Country Office for India and Sectoral Policies Department. http:// www.ilo.org/sector/Resources/publications/WCMS_781885/ lang--en/index.html

International Labour Organization, European Foundation for the Improvement of Living and Working Conditions, Mariya Aleksynska, Janine Berg, David Foden, Hannah Johnston, Agnès Parent-Thirion, Julie Vanderleyden, European Union, et Publications Office (2019) Working conditions in a global perspective. Publications Office 
of the European Union, Luxembourg, and International Labour Organization, Geneva. https://doi.org/10.2806/870542

ISO14044 (2006) ISO 14044:2006 — Management environnemental - Analyse du cycle de vie - Exigences et lignes directrices. https://www.iso.org/obp/ui/\#iso:std:iso:14044:ed-1:v1:fr

ISO26000 (2010) ISO 26000:2010 (En), Guidance on Social Responsibility . https://www.iso.org/obp/ui/\#iso:std:iso:26000:ed-1:v1:en

Jasinski D, Meredith J, et Kirwan K (2015) A comprehensive review of full cost accounting methods and their applicability to the automotive industry . J Clean Prod 108 (décembre): 1123-39. https://doi.org/10.1016/j.jclepro.2015.06.040

Johannessen B (2009) Building rural roads. International Labour Office. http://www.ilo.org/global/publications/ilo-bookstore/ order-online/books/WCMS_111496/lang--en/index.html

Jones S, Tefe M, Appiah-Opoku S (2015) Incorporating stakeholder input into transport project selection-a step towards urban prosperity in developing countries? Habitat Int 45:20-28

Jørgensen A, Lai LCH, et Hauschild MZ (2009) Assessing the validity of impact pathways for child labour and well-being in social life cycle assessment. Int J Life Cycle Assess 15(1):5. https://doi.org/ 10.1007/s11367-009-0131-3

Kamenopoulos SN, Zacharias A, et Komnitsas S (2016) Framework for sustainable mining of rare earth elements. In Rare Earths Industry, 111-20. Elsevier. https://doi.org/10.1016/B978-0-12802328-0.00007-3

Karlewski H, Lehmann A, Ruhland K, Finkbeiner M (2019) A practical approach for social life cycle assessment in the automotive industry. Resources 8(3):146. https://doi.org/10.3390/resou rces8030146

Keoleian GA, Miller S, De Kleine RD, et Mosley J (2012) Life cycle material data update for GREET model . CSS12-12. Center for Sustainable Systems - University of Michigan. http://css. snre.umich.edu/

Keseru I, Coosemans T, Gagatsi G, et Macharis C (2018) User-centric vision for mobility in 2030: participatory evaluation of scenarios by the multi-actor multi-criteria analysis (MAMCA). https:// zenodo.org/record/1483459\#.XI-3vbiNyUk

König A, Nicoletti L, Schröder D, Wolff S, Waclaw A, Lienkamp M (2021) An overview of parameter and cost for battery electric vehicles. World Electr Veh J 12(1):21. https://doi.org/10.3390/ wevj12010021

Kostiainen J, et Tuominen A (2019) Mobility as a service—stakeholders' challenges and potential implications . In Towards user-centric transport in europe: challenges, solutions and collaborations, édité par Beate Müller et Gereon Meyer, 239-54. Lecture Notes in Mobility. Cham: Springer International Publishing. https://doi. org/10.1007/978-3-319-99756-8_16

Kougias I, Alexandros N, Thiel C, et Szabó S (2020) Clean energy and transport pathways for islands: a stakeholder analysis using Q method . Transp Res D: Transp Environ 78: 102180

Lenzen M, Moran D, Kanemoto K, Geschke A (2013) Building Eora: a global multi-region input-output database at high country and sector resolution. Econ Syst Res 25(1):20-49. https://doi.org/10. 1080/09535314.2013.769938

Leurent F, Windisch E (2015) Benefits and costs of electric vehicles for the public finances: an integrated valuation model based on input-output analysis, with application to France. Res Transp Econ 50:51-62

L'Hostis A, Muller B, Meyer G, Bruckner A, Foldesi E, Dablanc L, Blanquart C et al (2016) MOBILITY4EU - D2.1 - Societal needs and requirements for future transportation and mobility as well as opportunities and challenges of current solutions . Research Report. IFSTTAR - Institut Français des Sciences et Technologies des Transports, de l'Aménagement et des Réseaux. https:// hal.archives-ouvertes.fr/hal-01486783
Lindenau M, Böhler-Baedeker S (2014) Citizen and stakeholder involvement: a precondition for sustainable urban mobility. Transp Res Procedia 4:347-360

Litmanen T, Jartti T, Rantala E (2016) Refining the preconditions of a social licence to operate (SLO): reflections on citizens' attitudes towards mining in two Finnish regions. Extr Ind Soc 3(3):782792. https://doi.org/10.1016/j.exis.2016.04.003

Loayza N, et Rigolini J (2016) The local impact of mining on poverty and inequality: evidence from the commodity boom in Peru . World Dev. 84 (août): 219-34. https://doi.org/10.1016/j. worlddev.2016.03.005

Lopez-Arboleda E, Sarmiento AT, Cardenas LM (2019) Systematic review of integrated sustainable transportation models for electric passenger vehicle diffusion. Sustainability 11(9):2513

Ludovico N, Dessi F, Bonaiuto M (2020) Stakeholders Mapping for sustainable biofuels: an innovative procedure based on computational text analysis and social network analysis. Sustainability 12(24): 10317

Macombe C (2019) Social life cycle assessment for industrial biotechnology . In . Berlin, Heidelberg: Springer Berlin Heidelberg. https://doi.org/10.1007/10_2019_99

Mahoney LS, Thorne L, Cecil L, et LaGore W (2013) A research note on standalone corporate social responsibility reports: signaling or greenwashing? Critic Perspect Account 24 (4): 350-59. https:// ideas.repec.org/a/eee/crpeac/v24y2013i4p350-359.html

Maister K, Di Noi C, Ciroth A, et Srocka M (2020) Product Social Impact Life Cycle Assessment (PSILCA) Database v.3 Documentation . Databse Documentation version 1.0. GreenDelta. https://www.openlca.org/wp-content/uploads/2020/06/PSILCA_ V3_manual.pdf

Mancini L, Eynard U, Eisfeldt F, Ciroth A, Blengini G, Pennington D (2019) Social assessment of raw materials supply chains. A LifeCycle-Based Analysis. https://doi.org/10.2760/470881

Mancini L, et Sala S (2018) Social impact assessment in the mining sector: review and comparison of indicators frameworks . Resour Policy 57 (août): 98-111. https://doi.org/10.1016/j. resourpol.2018.02.002

Mattila TJ (2018) Use of input-output analysis in LCA . In Life cycle assessment, édité par Michael Z. Hauschild, Ralph K. Rosenbaum, et Stig Irving Olsen, 349-72. Cham: Springer International Publishing. https://doi.org/10.1007/978-3-319-56475-3_14

McQuilken J, et Perks R (2021) 2020 state of the artisanal and small scale mining sector . International Labour Organization (ILO). https://delvedatabase.org/resources/2020-state-of-theartisanal-and-small-scale-mining-sector

Messagie M (2014) Life cycle analysis of the climate impact of electric vehicles . Vrije Universiteit Brussel- Research group MOBI. https://pdfs.semanticscholar.org/1eb5/ b7c002404326dca2391b2004daa56dc18028.pdf

Neugebauer S (2016) Enhancing life cycle sustainability assessment - tiered approach and new characterization models for social life cycle assessment and life cycle costing. Thèse de doctorat, berlin: Prozesswissenschaftender Technischen Universität Berlin. https://doi.org/10.14279/depositonce-5644

Neugebauer S, Traverso M, Scheumann R, Chang Y-J, Wolf K, Finkbeiner M (2014) Impact pathways to address social wellbeing and social justice in SLCA - fair wage and level of education. Sustainability 6(8):4839-4857. https://doi.org/10. 3390/su6084839

Newman W (2015) Health and safety concerns about the increasing use of mobility scooters on New Zealand roads . RCA Forum Research and Guidelines Steering Group report, 2. https://rcaforum.org.nz/ sites/public_files/images/Mobility\%20Scooters-Health\%20and\% 20Safety\%20Concerns\%20.pdf 
Noble J (2015) L'insécurité personnelle dans les transports en commun . Deviance et Societe 39 (3): 343-64. https://www.cairn.info/revuedeviance-et-societe-2015-3-page-343.html

Noel L, Rubens GZD, Sovacool BK (2018) Optimizing innovation, carbon and health in transport: assessing socially optimal electric mobility and vehicle-to-grid pathways in Denmark. Energy 153:628-637

Norris GA (2006) Social impacts in product life cycles - towards life cycle attribute assessment. Int J Life Cycle Assess 11(1):97-104. https://doi.org/10.1065/lca2006.04.017

Northey SA, Gavin M, Mudd T, Werner T, Nawshad H, et Mohan Y (2019) Sustainable water management and improved corporate reporting in mining. Water Resour. Ind. 21 (juin): 100104. https://doi.org/10.1016/j.wri.2018.100104

Numbeo (2019) Pollution index by country 2019 . 2019. https://www. numbeo.com/pollution/rankings_by_country.jsp?title=2019

OECD. (2016). OECD Due Diligence Guidance for Responsible Supply Chains of Minerals from Conflict-Affected and High Risk Areas: Third Edition. OECD. https://doi.org/10.1787/ 9789264252479-en

OECD. (2019a). OECD Reference Note on Environmental and Social Considerations in Quality Infrastructure (p. 23). OECD. https:// www.oecd.org/g20/summits/osaka/OECD-Reference-Note-onEnvironmental-and-Social-Considerations.pdf

OECD. (2019b). Interconnected supply chains: A comprehensive look at due diligence challenges and opportunities sourcing cobalt and copper from the Democratic Republic of the Congo. OECD. https://mneguidelines.oecd.org/Interconnectec-supplychains-a-comprehensive-look-at-due-diligence-challenges-andopportunities-sourcing-cobalt-and-copper-from-the-DRC.pdf

OECD (2021) Trends in stakeholder reporting: mineral supply chains . OECD. https://mneguidelines.oecd.org/trends-in-stakeholderreporting-mineral-supply-chains.pdf

OIE (2017) Les enjeux de l'intégration des véhicules électriques dans le système électrique. Fiche pédagogique présenté à OIE est le portail économique et statistique de l'Union Française de l'Électricité. https://observatoire-electricite.fr/IMG/pdf/oie_-fiche_pedago_mobilite_sept_2017.pdf

Omahne V, Knez M, Obrecht M (2021) Social aspects of electric vehicles research - trends and relations to sustainable development goals. World Electr Veh J 12(1):15

Onat NC, Kucukvar M, Tatari O, Egilmez G (2016) Integration of system dynamics approach toward deepening and broadening the life cycle sustainability assessment framework: a case for electric vehicles. Int J Life Cycle Assess 21(7):1009-1034. https://doi. org/10.1007/s11367-016-1070-4

ONISR (2019) La sécurité routière en France: Bilan de l'accidentalité de l'année 2018 . Observatoire national interministériel de sécurité routière. http://www.onisr.securite-routiere.gouv.fr

Orozco, CG (2018) The global mining cluster and decoding sustainable mining J Hist Archaeol Anthropolog Sci 3 (1). https://doi.org/10. 15406/jhaas.2018.03.00074

Osorio-Tejada JL, Llera-Sastresa E, Scarpellini S, Hashim AH (2020) An integrated social life cycle assessment of freight transport systems. Int J Life Cycle Assess 25(6):1088-1105. https://doi. org/10.1007/s11367-019-01692-w

Ostojski L (2018) Données collectées par le véhicule, un nouvel Eldorado ? , L'Argus de l'assurance, mai. https://www.argusdelassurance.com/ dossier-ja/donnees-collectees-par-le-vehicule-un-nouvel-eldorado. 129970

Pastor MM, Schatz T, Traverso M, Wagner V, Hinrichsen O (2018) Social aspects of water consumption: risk of access to unimproved drinking water and to unimproved sanitation facilities - an example from the automobile industry. Int $\mathbf{J}$ Life Cycle Assess 23(4):940-956. https://doi.org/10.1007/ s11367-017-1342-7
Patil LN, Khairnar HP (2021) Investigation of human safety based on pedestrian perceptions associated to silent nature of electric vehicle. Transdisciplinary Research and Education Center for Green Technologies 8:280-289. https://doi.org/10.5109/ 4480704

Pira Le, Michela MI, Inturri G, Pluchino A, Rapisarda A (2016) Modelling stakeholder participation in transport planning. Case Stud Transp Policy 4(3):230-238

Pérez-López, P, Gumersindo F, et Moreira MT (2018) Sustainability assessment of blue biotechnology processes: addressing environmental, social and economic dimensions . In Designing sustainable technologies, products and policies: from science to innovation, edited by Enrico Benetto, Kilian Gericke, et Mélanie Guiton, 475-86. Cham: Springer International Publishing. https:// doi.org/10.1007/978-3-319-66981-6_53

Peron M (2010) La communication dans les transports publics interurbains de voyageurs. Ecole Nationale des Ponts et Chaussées. https://pastel.archives-ouvertes.fr/tel-00523273/document

Petti L, Serreli M, Di Cesare S (2016) Systematic literature review in social life cycle assessment. Int J Life Cycle Assess 23(3):422431. https://doi.org/10.1007/s11367-016-1135-4

Peugeot (2020) Configurateur Peugeot 208 I Votre citadine sur-mesure . 2020. https://www.peugeot.fr/nos-vehicules/e-208/configurez. $\mathrm{html} /$ finitions

Renault (2020) RENAULT ZOE E-TECH ELECTRIQUE . 2020. https://www.renault.fr/vehicules-electriques/zoe.html

RTE (2015) Valorisation socio-économique des réseaux électriques intelligents-Méthodologie et premiers résultats . Rapport d'étude. Paris, France: Réseau de transport d'électricité-ademe. https:// www.rte-france.com/sites/default/files/rei_bd_1.pdf

RTE (2019) Enjeux du développement de l'électromobilité pour le système électrique . Principaux résultats. https://www.rte-france. com/sites/default/files/electromobilite_synthese_9.pdf

Rugani B, Panasiuk D, Benetto E (2012) An input-output based framework to evaluate human labour in life cycle assessment. Int J Life Cycle Assess 17(6):795-812. https://doi.org/10.1007/ s11367-012-0403-1

Russo-Spena T, Tregua M, De Chiara A (2018) Trends and drivers in CSR disclosure: a focus on reporting practices in the automotive industry. J Bus Ethics 151(2):563-578. https://doi.org/10.1007/ s10551-016-3235-2

Schlör H, Venghaus S, Zapp P, Marx J, Schreiber A, et. Hake J-Fr (2018) The energy-mineral-society nexus - a social LCA model. Appl Energy 228: 999-1008. https://doi.org/10.1016/j.apenergy. 2018.06.048

Silva M, Elton V, Signoretti G, Silva I, Silva D, et Ferrari P (2018) A customer feedback platform for vehicle manufacturing compliant with Industry 4.0 vision. Sensors (Basel, Switzerland) 18 (10). https://doi.org/10.3390/s18103298

Smaragdakis A, Kamenopoulos S, Tsoutsos T (2020) How risky is the introduction of fuel cell electric vehicles in a Mediterranean town? Int J Hydrog Energy 45(35):18075-18088

Spickermann A, Grienitz V, Heiko A (2014) Heading towards a multimodal city of the future?: multi-stakeholder scenarios for urban mobility. Technol Forecast Soc Change 89:201-221

The European Parliament and the Council (2014) Regulation (EU) No 333/2014 of the European Parliament and of the Council of 11 March 2014 Amending Regulation (EC) No 443/2009 to Define the Modalities for Reaching the 2020 Target to Reduce CO 2 Emissions from New Passenger Cars. OJ L. 103. http:// data.europa.eu/eli/reg/2014/333/oj/eng

Tseng H-K, Wu JS, et Liu X (2013) Affordability of electric vehicles for a sustainable transport system: an economic and environmental analysis. Energy Policy 61: 441-47. https://doi.org/10.1016/j. enpol.2013.06.026 
Turnbull P (2013) Promoting the Employment of Women in the Transport Sector Obstacles and Policy Options. Working Paper No. 298. Geneva: International Labour Organization (ILO). /docman/ rosasec/efe474/16711.pdf

Uwe T, Mock P, Lutsey N, et Campestrini A (2016) Comparison of leading electric vehicle policy and deployment in Europe. White paper. Intern Council Clean Transport. https://theicct.org/sites/ default/files/publications/ICCT_EVpolicies-Europe-201605.pdf

UE, et CNIL (2018) Le règlement général sur la protection des données - RGPD I CNIL. https://www.cnil.fr/fr/reglement-europ een-protection-donnees\#

UNEP (2018) Shout it Out: Communicating Products' Social Impacts - A white paper of the one planet network consumer information programme. http://www.oneplanetnetwork.org/ sites/default/files/white_paper_-_communicating_products_ social_impacts_ci-scp_2018.pdf

UNEP (2020) Guidelines for social life cycle assessment of products and organizations. Édité par C Benoît Norris, Marzia Traverso, Sabrina Neugebauer, Elisabeth Ekener, T Schaubroeck, Sara Russo Garrido, Marcus Berger, et al. United Nations Environment Programme (UNEP). https://www.lifecycleinitiative.org/ wp-content/uploads/2020/12/Guidelines-for-Social-Life-CycleAssessment-of-Products-and-Organizations-2020-sml.pdf

UNEP/SETAC (2009) Guidelines for social life cycle assessment of products. Édité par Catherine Benoît, Bernard Mazijn, CIRAIG, et Processes and Services Interuniversity Research Centre for the Life Cycle of Producs. Paris, France: United Nations Environment Programme. http://ra.ocls.ca/ra/login.aspx?inst=centennial\&url= https://www.deslibris.ca/ID/236529

UN-Global Compact, et KPMG (2016) SDG Industry Matrix for Transportation. United Nations- Global Compact and KPMG International Cooperative. https://assets.kpmg/content/dam/kpmg/xx/ pdf/2017/05/sdg-transportation.pdf

United Nations (2012) Guiding Principles on business and human rightsimplementing the United Nations "Protect, Respect and Remedy" Framework. Genève: United NATIONS. https://www.ohchr.org/ documents/publications/guidingprinciplesbusinesshr_en.pdf.

Walle M (2001) Safety \& health in small-scale surface mines, a handbook. Geneva: International Labour Office. https://www.ilo. org/wcmsp5/groups/public/---ed_dialogue/---sector/documents/ publication/wcms_162738.pdf

Werker J, Wulf C, Zapp P, Schreiber A, Marx J (2019) Social LCA for rare earth $\mathrm{NdFeB}$ permanent magnets. Sustain Prod Consum 19:257-269. https://doi.org/10.1016/j.spc.2019.07.006

WHO (2015) Health 2020: Transport and health. World Health Organization: Europe. https://www.euro.who.int/_data/assets/pdf_file/ 0005/286421/Transport_E.pdf

World Bank. (2006). Social Analysis in Transports Projects: Guidelines for Incorporating Social Dimensions into Bank-Supported Projects (p. 54). World Bank-Social Development Department. https://www.ssatp.org/sites/ssatp/files/publications/HTML/Gender-RG/Source/20/20documents/Tool/20Kits/20\&/20Guides/ Social/20Analysis/SA_Transport_wb.pdf

World Bank (2010) Social development and infrastructure- Making Transport Work for Women and Men Tools for Task Teams.
68750. Wold Bank- Social Development Department. https:// openknowledge.worldbank.org/bitstream/handle/10986/12555/ 687500ESW0P1100ng0Transport0WorkFor.pdf? sequence $=1 \&$ isAllowed $=\mathrm{y}$.

World Bank (2017) World Development Indicators 2017. Washington DC: World Bank. https://openknowledge.worldbank.org/handle/ 10986/26447

World Bank. (2020). Violence Against Women and Girls in Public Transport: Policy Recommendations for Mexico City. World Bank,. https://openknowledge.worldbank.org/bitstream/handle/10986/35015/Violence-Against-Women-and-Girls-in-Public-Transport-Policy-Recommendations-for-Mexico-City.pdf? sequence $=1 \&$ is Allowed $=\mathrm{y}$

Zamagni A (2019) Investigation of status and needs for social LCA The SCORELCA Project and beyond Background and Research Questions. Présenté à Conference: Social LCA metrics Workshop. https://doi.org/10.13140/RG.2.2.26537.44645

Zamagni A, Pesonen H-L, Swarr T (2013) From LCA to life cycle sustainability assessment: concept, practice and future directions. Int J Life Cycle Assess 18(9):1637-1641. https://doi.org/10.1007/ s11367-013-0648-3

Zambrano-Gutiérrez JC, Nicholson-Crotty S, Carley S, Siddiki S (2018) The role of public policy in technology diffusion: the case of plug-in electric vehicles. Environ Sci Technol 52(19):10914 10922. https://doi.org/10.1021/acs.est.8b01149

Zambre A (2015) Stakeholder's perspectives on integrating sustainability in project management. Dublin Business School. https:// esource.dbs.ie/handle/10788/2838

Zanchi L, Delogu M, Zamagni A, Pierini M (2018) Analysis of the main elements affecting social LCA applications: challenges for the automotive sector. Int J Life Cycle Assess 23(3):519-535. https://doi.org/10.1007/s11367-016-1176-8

Zanchi L, Zamagni A, Maltese S, Riccomagno R, et Delogu M (2020) Social assessment in the design phase of automotive component using the product social impact assessment method. In Perspectives on social LCA: contributions from the 6th International Conference, édité par Marzia Traverso, Luigia Petti, et Alessandra Zamagni, 105-17. SpringerBriefs in Environmental Science. Cham: Springer International Publishing. https://doi.org/10.1007/978-3030-01508-4_10

Zhang A, Moffat K, Lacey J, Wang J, González R, Uribe K, Cui L, Dai Y (2015) Understanding the social licence to operate of mining at the national scale: a comparative study of Australia, China and Chile. J Clean Prod 108:1063-1072. https://doi.org/10.1016/j. jclepro.2015.07.097

Zimmer K, Fröhling M, Breun P, Schultmann F (2017) Assessing social risks of global supply chains: a quantitative analytical approach and its application to supplier selection in the German automotive industry. J Clean Prod 149:96-109. https://doi.org/10.1016/j. jclepro.2017.02.041

Publisher's Note Springer Nature remains neutral with regard to jurisdictional claims in published maps and institutional affiliations.

\section{Authors and Affiliations}

\section{Ghada Bouillass $^{1}(\mathbb{D})$ Isabelle Blanc ${ }^{1}(\mathbb{D}) \cdot$ Paula Perez-Lopez ${ }^{1}(\mathbb{C}$}

Isabelle Blanc

isabelle.blanc@mines-paristech.fr

Paula Perez-Lopez

paula.perez_lopez@mines-paristech.fr
MINES ParisTech, Université PSL, Centre Observation Impacts Energie (O.I.E.), 06904 Sophia Antipolis, France 